Provided for non-commercial research and education use. Not for reproduction, distribution or commercial use.

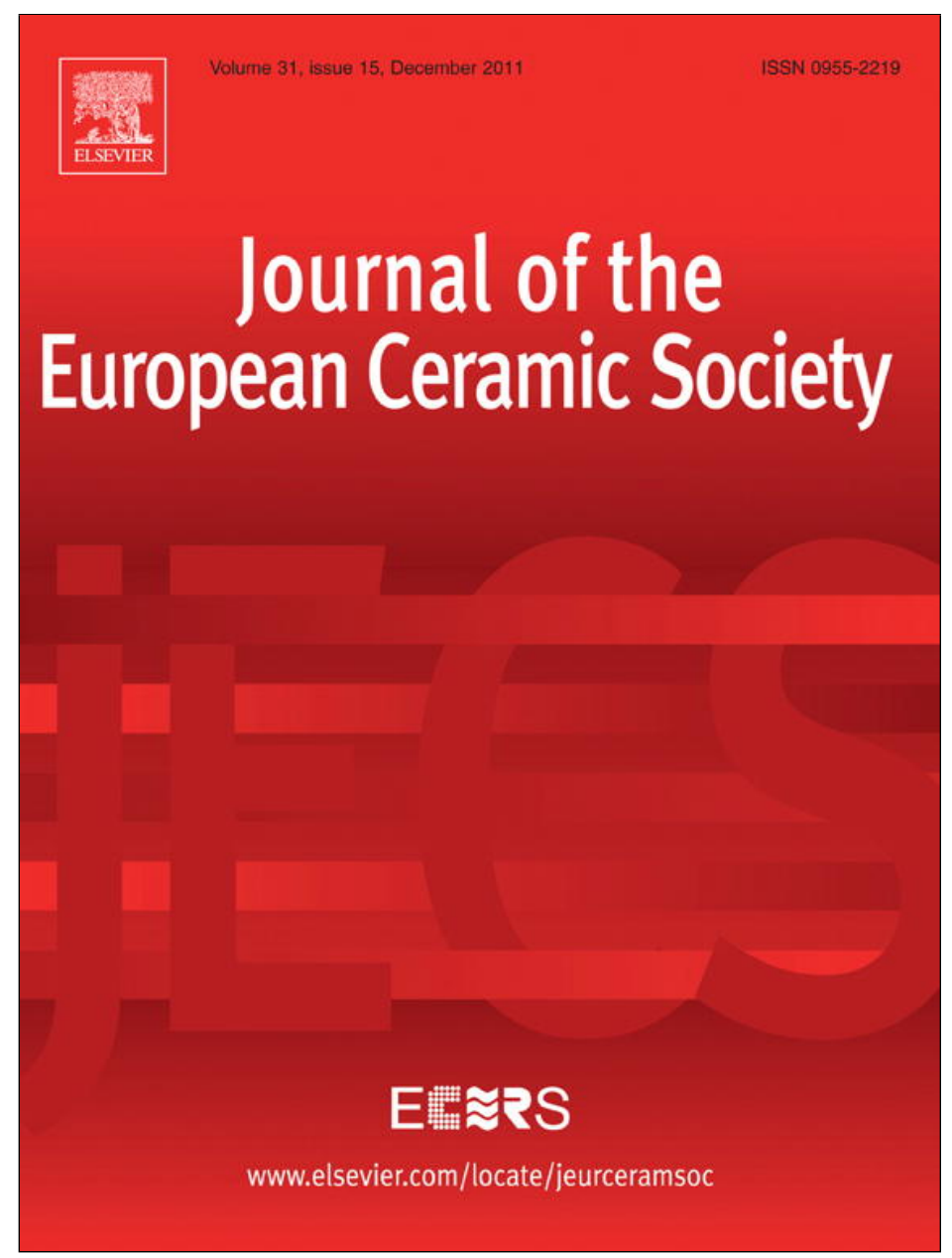

This article appeared in a journal published by Elsevier. The attached copy is furnished to the author for internal non-commercial research and education use, including for instruction at the authors institution and sharing with colleagues.

Other uses, including reproduction and distribution, or selling or licensing copies, or posting to personal, institutional or third party websites are prohibited.

In most cases authors are permitted to post their version of the article (e.g. in Word or Tex form) to their personal website or institutional repository. Authors requiring further information regarding Elsevier's archiving and manuscript policies are encouraged to visit:

http://www.elsevier.com/copyright 


\title{
Atomistic modeling of dopant segregation in $\alpha$-alumina ceramics: Coverage dependent energy of segregation and nominal dopant solubility
}

\author{
S. Galmarini, U. Aschauer*,1, A. Tewari, Y. Aman ${ }^{2}$, C. Van Gestel, P. Bowen \\ Laboratoire de technologie des poudres, Ecole polytechnique fédérale de Lausanne, 1015 Lausanne, Switzerland \\ Received 4 April 2011; received in revised form 22 June 2011; accepted 10 July 2011 \\ Available online 4 August 2011
}

\begin{abstract}
Microstructural control is a key aspect in producing ceramics with tailored properties and is often achieved by using dopants in a rather empirical fashion. Atomic scale simulations could provide much needed insight but the long-standing challenge of linking simulation results on isolated grain boundaries to those measured in real ceramics needs to be resolved. Here a novel Monte-Carlo simulation method based on a microstructural model in combination with energies obtained from atomic scale energy minimization is presented. This approach allows, for the first time, the prediction of the nominal solubility of dopants (Y, La and $\mathrm{Mg}$ ) in a ceramic purely from theory.

Results compare well with segregation/precipitation data as a function of grain size, found in the literature. The method can therefore be used in developing experimental guidelines for the effective use of dopants in ceramic production, thus accelerating the development of novel materials required for innovative applications.
\end{abstract}

(C) 2011 Elsevier Ltd. All rights reserved.

Keywords: $\mathrm{Al}_{2} \mathrm{O}_{3}$; Interfaces; Grain size; Dopant solubility; Atomistic simulation

\section{Introduction}

Properties of ceramic materials generally show a strong dependence on their microstructure. It is therefore desirable to engineer the microstructure so as to obtain the best possible performance for a given application. Microstructural parameters such as the grain size and shape are governed during the synthesis of a ceramic by the nature and mobility of grain boundaries present in the material. Control over these microstructural parameters in ceramics is typically achieved by a precise control over processing conditions and the use of dopant elements. It is well established that many dopant elements routinely added to ceramics (for example $\mathrm{Y}, \mathrm{La}$ and $\mathrm{Mg}$ in alumina) have, due to their larger ionic size, a low bulk solubility ${ }^{1}$ and a marked

\footnotetext{
* Corresponding author at: Materials Theory, ETH Zürich, Wolfgang-PauliStrasse 27, 8093 Zürich, Switzerland. Tel.: +41 04463394 38; fax: +410446331459.

E-mail address: uli.aschauer@mat.ethz.ch (U. Aschauer).

1 Present address: Materials Theory, ETH Zürich, Zürich, Switzerland.

2 Present address: DEN/DMN/SRMA/LA2M, CEA Saclay, 91191 Gif-surYvette Cedex, France.
}

tendency to segregate to grain boundaries. ${ }^{2}$ Once present at interfaces they can affect properties such as interface mobility and transport in the grain boundary plane. More recently it has been established that dopants also have a marked effect on the structure and thermodynamic stability of grain boundaries by forming so called grain boundary complexions. ${ }^{3}$ While it was assumed for many years that grain boundary structures control the concentration of dopants in their vicinity this represents a paradigm shift in the sense that the dopant concentration can in fact also control the structure of the grain boundary. This indicates that there is a strong interdependence between the concentration of dopants present at the interface and the interface structure.

Dopant compositions and concentrations and their effect on the final microstructure have typically been optimized by an empirical trial and error fashion, without much understanding of the doping mechanism or even its location within the microstructure. The effective use of dopants during ceramic synthesis would greatly benefit from a more fundamental understanding of how dopants affect various properties such as grain boundary structure, interfacial energies and diffusion processes. Albeit with recent advances in experimental analysis techniques 
(Ref. 3 and references therein), it is still very challenging to experimentally explain and quantify the influence of dopant segregation on interfacial properties at an atomic level. This is due to the large number of parameters such as the crystallography of an interface and the concentration and arrangement of dopants (i.e. complexion ${ }^{3}$ ), which dictate the thermodynamic stability and mobility of the interface but are difficult to characterize simultaneously on the same interface.

Atomistic simulation methods represent an interesting alternative method to experiment as they allow the simultaneous study of structures and thermodynamics (i.e. energies) resulting from dopant segregation to surfaces and grain boundaries. One challenge to overcome in order to render these simulations more useful for comparison with experiment is that usually only isolated grain boundaries are simulated. We present here an approach aiming to bridge this gap between simulations and experiment by using results from atomistic simulations in larger scale Monte-Carlo simulations combined with a microstructural model in a bottom-up multi-scale modeling approach.

In the present work we focus on polycrystalline alumina as it is one of the most important ceramic materials with many applications, exhibiting a remarkable structural stability when used under extreme mechanical, electrical or refractory conditions. ${ }^{4}$ Structural analysis techniques, such as scanning transmission electron microscopy (STEM) and secondary ion mass spectroscopy (SIMS), have shown that upon doping with oversized elements segregation to surfaces and grain boundaries occurs. As a result the local chemical composition of the interface is modified, ${ }^{1,5}$ the extent depending on the exact nature of the boundary and dopant. ${ }^{3}$ Depending on their size, concentration and arrangement, segregated dopant ions may either slow down or accelerate grain boundary transport and mobility. ${ }^{3}$

Energy minimization techniques based on empirical interatomic potentials are used in the present work to investigate the segregation of lanthanum (La), gadolinium $(\mathrm{Gd})$, ytterbium $(\mathrm{Yb})$ and magnesium $(\mathrm{Mg})$ dopants to nine low energy surfaces and their respective mirror twin grain boundaries of alumina. This technique has previously been used for Yttrium dopants and showed segregation to be strongly dependent on the type of surface or grain boundary. Segregation was predicted to have a significant influence on interfacial energies ${ }^{6}$ thus influencing both grain boundary structure and stability.

When a sufficiently large set of interfaces is calculated, their average segregation behavior should be representative for alumina ceramics and should therefore allow us to gain valuable insights into dopant segregation in a polycrystalline material. A Monte-Carlo scheme based on energies obtained from energy minimization is then used to assess the nominal solubility of dopants in a ceramic as a function of its grain size using a microstructural model based on regular polyhedra. ${ }^{7}$ This represents a very important development as it establishes a link between quantities available from experiments (segregation and precipitation maps as a function of grain size for $\mathrm{Y}, \mathrm{La}$ and $\mathrm{Mg}$ doped alumina ceramics) with those resulting from atomistic calculations. Bridging this gap between the atomistic and microstructural scale opens new pathways towards understanding fundamental dopant mechanisms important in microstructural engineering.

\section{Methods}

The simulation approach used in the present work consists of three stages as shown in Fig. 1. Results from one stage are used as input data in the following stage. A brief overview of the three stages is given here followed by a more detailed description of each in a separate section. First the total energies of different arrangements of dopants at various concentrations in the proximity of surfaces and grain boundaries are computed based on classical interatomic potentials (Fig. 1a). This data is compiled into a lookup table for use in subsequent Monte Carlo simulations, in which the average enthalpy of segregation as a function of the interface dopant concentration is determined (Fig. 1b). This function and its derivative with respect to the interface dopant concentration are then used in the final step to determine the nominal dopant solubility within a ceramic microstructure of given grain size as described by an analytical microstructure model (Fig. 1c).
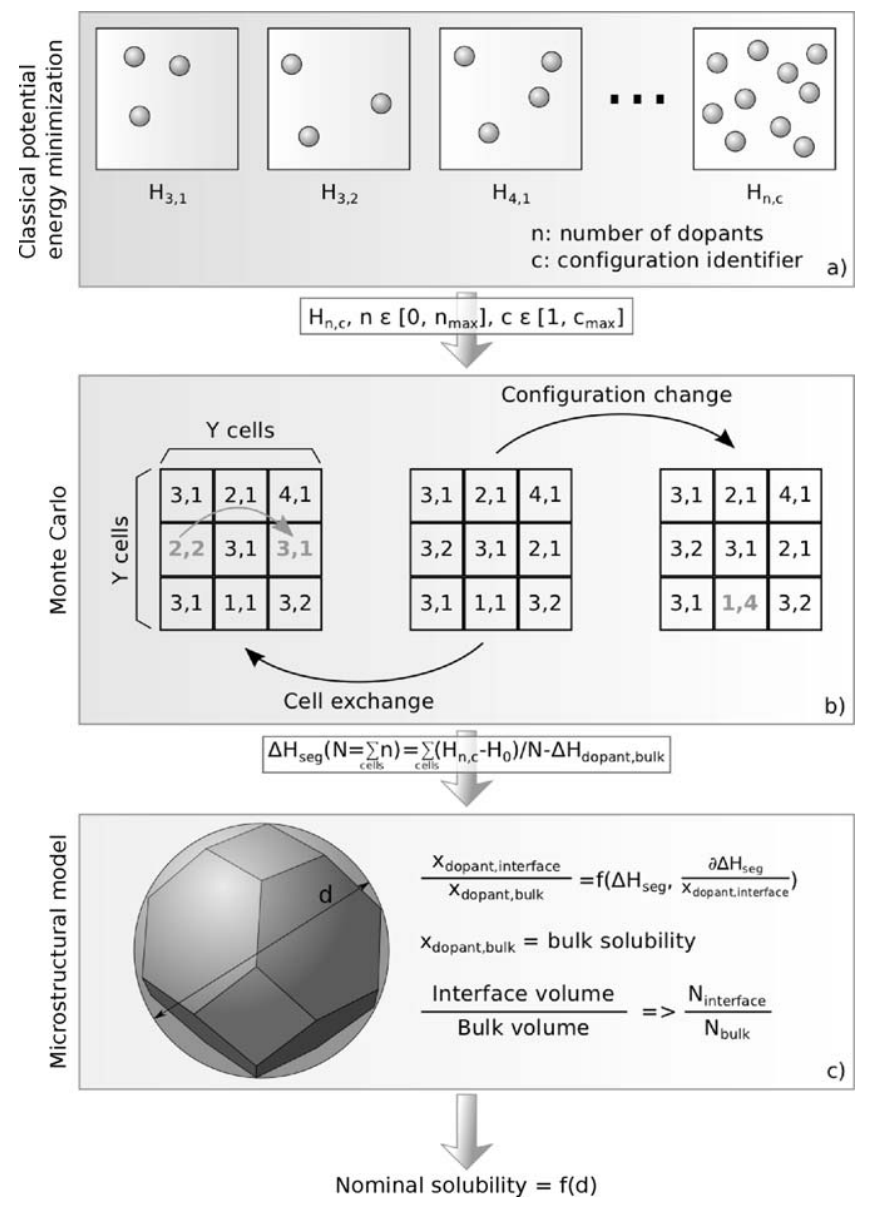

Fig. 1. Schematic representation of the simulation approach including (a) classical interatomic potential calculation to precompute energies, (b) use of these energies in Monte Carlo simulations and (c) prediction of the nominal solubility based on the computed coverage dependent enthalpy of segregation using a microstructural model. 


\subsection{Atomistic calculations}

A detailed description of the computational method can be found elsewhere ${ }^{6,8,9}$ and only a brief description will be given here. All atomistic calculations are based on the Born model for solids ${ }^{10}$ as implemented in METADISE, ${ }^{11}$ which describes interatomic interactions by pair-wise sums over all atoms. In order to correctly model the highly polarizable oxygen ion, the core-shell model by Dick and Overhauser ${ }^{12}$ has been applied. The potential model used is the one developed by Lewis and Catlow $^{13}$ and the initial alumina crystal structure has been taken from Liu et al. ${ }^{14}$ Surface and grain boundary structures were set up as $2 \mathrm{D}$ periodic slab models, applying a two-region model in the direction perpendicular to the interface. In this model the ions within $\sim 9 \AA$ of the interface are allowed to relax (interface region) and those further from the interface held fixed (bulk region). The total energy, i.e. the sum over all interactions in the system, was then minimized using the Newton-Raphson method until the energy converged to a minimum. This approach was shown to yield results which compare well to both experiment and first-principle calculations. ${ }^{6}$ The resulting structures were considered to represent undoped interfaces at equilibrium and the interfacial energy $\gamma$ was calculated using Eq. (1).

$\gamma=\frac{H_{\text {interf }}-m H_{\text {bulk }}}{A}$

$H_{\text {interf }}$ being the potential energy of the interface slab, $H_{b u l k}$ the potential energy of a bulk unit-cell and $m$ the number of bulk unit-cells contained in the interface slab of area $A$.

Subsequently La, Gd, $\mathrm{Yb}$ and $\mathrm{Mg}$ dopant ions were dissolved into the undoped interfaces by substituting them on Al sites. As $\mathrm{Mg}$ is aliovalent, for each pair of $\mathrm{Mg}$ ions an oxygen vacancy was created in the structure so as to preserve charge neutrality. The probability-based approach outlined in ${ }^{9}$ was used to restrict the otherwise vast number of possible permutations. The average enthalpy of dissolution per dopant ion for a certain dopant configuration $c$ with respect to a stable pure dopant oxide phase has been calculated as given by Eq. (2).

$\Delta H_{s o l}(n, c)=\frac{1}{n}\left[H(n, c)+n H_{\mathrm{Al}}-H(0)-n H_{D O}\right]$

where $H(n, c)$ is the potential energy of the structure containing $n$ dopant ions in configuration $c$ and $H_{\mathrm{Al}}$ and $H_{D O}$ are the lattice energies per cation in pure alumina and the stable dopant oxide respectively. At the solubility limit $\Delta H_{\text {sol }}$ should be approximately zero. It should be noted that by using the pure dopant oxide phase instead of a real precipitate phase containing both cations, computed dissolution enthalpies represent an upper bound as precipitate phases should generally be more stable than these dopant oxide phases. Another thermodynamic quantity of interest is the average enthalpy of segregation per dopant ion ${ }^{15}$ in a structure containing $n$ dopant ions in a configuration $c$, given by Eq. (3).

$\Delta H_{s e g}(n, c)=\frac{1}{n}\left[H(n, c)-H(0)-n \Delta H_{b}\right]$
$\Delta H_{b}$ being the change in enthalpy when inserting a dopant ion in the bulk material, which has been evaluated using the Mott-Littleton ${ }^{16}$ approach, implemented in the GULP ${ }^{17,18}$ code. A negative value for the enthalpy of segregation indicates that segregation of dopant ions towards the interface is energetically favorable.

\subsection{Nominal solubility of dopants}

As high resolution TEM images of doped $\alpha$-alumina grain boundaries ${ }^{19-21}$ are rare, one challenge in the present study was to link the obtained simulation results to experimental observations on ceramics. Moreover as TEM experiments are usually carried out on well-defined bicrystals, they can be used to validate the atomistic simulation approach but do not allow a link with sintered ceramic microstructures containing a series of different grain boundaries. Such a link could however be provided by calculating the nominal solubility of the different dopants in representative $\alpha$-alumina model microstructures. The dopants considered in the present study (Y, Mg, La, Gd and $\mathrm{Yb}$ ) segregate strongly to $\alpha$-alumina interfaces. Their bulk solubility is low and the nominal solubility in a powder or a ceramic will depend strongly on the solubility at surfaces and grain boundaries respectively. Several methods to predict interface concentrations in equilibrium with a saturated bulk have been developed. ${ }^{15,22}$ The more sophisticated analytical method described in the latter reference takes into account different sublattices with different segregation energies and nearest neighbor interactions. In $\alpha$-alumina however nearest neighbor interactions alone seem inadequate, as previous energy minimization calculations of various dopant configurations have shown the segregation energies to be strongly affected by the underlying atomic interface structure, ${ }^{6}$ in agreement with the concept of grain boundary complexions. ${ }^{3}$

According to Mackrodt and Tasker, knowing the mean segregation energy $\Delta H_{\text {seg }}$ as a function of the interface cationic ratio $x_{i}$ of dopant to $\mathrm{Al}$ ions, the interface dopant ion concentration in equilibrium with a certain bulk cationic ratio $x_{b}$ (e.g. bulk saturation) is given by Eq. (4) ${ }^{15}$ (see Supporting Information section S6 for more information).

$x_{i}=x_{b} \cdot \exp \left[-\frac{1}{k T}\left(\Delta H_{\text {seg }}+x_{i}\left(x_{i}+1\right) \frac{\partial \Delta H_{\text {seg }}}{\partial x_{i}}\right)\right]$

where $k$ is the Boltzmann constant and $T$ is the absolute temperature. To obtain the mean segregation energy $\Delta H_{\text {seg }}$ as well as its derivative with respect to $x_{i}$ a Monte Carlo method was employed to simulate the dopant distribution at the interface.

\subsubsection{Monte Carlo method}

To calculate the mean segregation energy $\Delta H_{s e g}$, the interface was divided into cells with the same in-plane dimensions as the simulation cell used during the energy minimization calculations. These cells were considered to have the same interaction as in the periodic energy minimization calculations, which would correspond to the case of a homogeneous interface concentration. While neglecting the effect of an inhomogeneous dopant 
distribution on the energy is an approximation in the description of the variation of $\Delta H_{s e g}$ with $x_{i}$, it should in most cases be valid as most cells are in the same low energy configuration. In the small number of cases where two configurations with different concentrations are highly populated, the error due to this approximation is likely to be more marked.

In this setup, each cell is represented by two parameters: one specifies the number of dopants in the cell and the other indicates the arrangement of these dopants (Fig. 1(b)). The energy corresponding to a specific combination of these two parameters is obtained via an energy table pre-computed by energy minimization. Energies of configurations not taken into account by the probabilistic approach used in the energy minimization calculations ${ }^{6,8,9}$ are approximated by the highest calculated energy. As these high-energy states are essentially unoccupied their exact energy is unimportant.

Two different Monte Carlo moves have been considered. The first one changes the configuration of the dopants within a cell while the second extracts a dopant from one cell and introduces it into a different cell (Fig. 1(b)). Both steps do not influence the total concentration of dopants in the interface. Each move was accepted or rejected according to the acceptance probability calculated with Eq. (5).

$a c c=\min \left(1 ; \exp \left(-\frac{\Delta H}{k T}\right)\right)$

where $\Delta H$ is the change in energy associated with the move. The temperature $T$ was considered to be $1600^{\circ} \mathrm{C}$ for all MonteCarlo calculations. The random number for acceptance was drawn using the GNU Scientific Library (GSL) ranlxd2 random number generator, ${ }^{23}$ the validity of which for Monte Carlo calculations has been reported by different authors. ${ }^{24,25}$ To enhance convergence, states have been divided into classes of similar energies. Sampling of possible moves was restricted to neighboring classes, which permits a faster convergence without introducing a bias as long as classes have the same size. For each interface after an equilibration period of 50,000 steps the mean energy was calculated over the next 25,000 steps. The dopant concentration was then increased by 100 dopants per 1000 cells and after 25,000 steps of equilibration the mean energy was again calculated over the next 25,000 steps. Since Eq. (4) is very sensitive to the derivative of $\Delta H_{\text {seg }}$ with respect to $x_{i}$, a linear interpolation of the Monte Carlo data would be insufficient to get a smooth $x_{i}=f\left(x_{b}\right)$ curve. Therefore for low concentrations the resulting points of the $\Delta H_{\text {seg }}\left(x_{i}\right)$ curves have been interpolated by a local polynomial nonparametric regression estimator. ${ }^{26}$ For high concentrations $\Delta H_{\text {seg }}\left(x_{i}\right)$ closely follows the relation reported by Mackrodt an Tasker ${ }^{15}$ as given by Eq. (6).

$\Delta H_{\text {seg }}\left(x_{i}\right)=H_{0}-\lambda\left(1+\frac{1}{x_{i}}\right)$

where $H_{0}$ and $\lambda$ are constants fitted to the calculated $\Delta H_{\text {seg }}\left(x_{i}\right)$ using least squares. Subsequently the $x_{i}=f\left(x_{b}\right)$ curve was calculated with Eq. (4) and the interface saturation concentration $x_{i, s a t}$ in equilibrium with the bulk saturation concentration $x_{b, s a t}$ determined by linear interpolation between calculated points.

\subsubsection{Microstructural model}

Once $x_{i, s a t}$ is known for all interfaces, the nominal solubility of a dopant in a powder or ceramic can be calculated. For this purpose the grains in both powder and ceramic were approximated by truncated octahedrons, the specific interface area of which is given by Eq. (7).

$\frac{A}{V}=\frac{\sqrt{5}(3+6 \sqrt{3})}{4 d_{g}}$

where $d_{g}$ is the particle/grain size i.e. twice the circum radius of the truncated octahedrons. The nominal solubility $x_{n}$ was finally approximated as the ratio of the total number of dopant ions in the bulk $\left(N_{D, \text { bulk }}\right)$ and grain boundaries $\left(N_{D, G B}\right)$ to the total number of $\mathrm{Al}$ ions $\left(N_{\mathrm{Al}, \text { bulk }}+N_{\mathrm{Al}, G B}\right)$ as given by Eq. (8).

$x_{n}=\frac{N_{D, \text { bulk }}+N_{D, G B}}{N_{\mathrm{Al}, \text { bulk }}+N_{\mathrm{Al}, G B}}=\frac{\rho_{\mathrm{Al}} \cdot c_{b}+0.5 \cdot\left\langle\Gamma_{\text {sat }}\right\rangle(A / V)}{\rho_{\mathrm{Al}} \cdot\left(1-c_{b}\right)-0.5 \cdot\left\langle\Gamma_{\text {sat }}\right\rangle(A / V)}$

where $\rho_{\mathrm{Al}}$ is the Al site density (sites/volume) in $\alpha$-alumina, $c_{b}$ is the bulk solubility and $\left\langle\Gamma_{\text {sat }}\right\rangle$ is the mean interface dopant concentration (i.e. dopants per interface area) at saturation and the factor 0.5 is required as the concentration in only one halfcrystal is being considered.

\section{Results and discussion}

The results will be divided into five sections. First the calculated pristine surface and grain boundary structures will be shown. Then lanthanum (La) doping is treated in detail, gadolinium $(\mathrm{Gd})$ and ytterbium $(\mathrm{Yb})$ are discussed briefly due to their similarity with La. Results for the magnesium (Mg) dopant are shown next before looking at the nominal solubility of yttrium (Y), La and $\mathrm{Mg}$ dopants.

\subsection{Surface and grain boundary structures}

Interfacial energies and structures of nine low index surfaces in $\alpha-\mathrm{Al}_{2} \mathrm{O}_{3}$ and their respective mirror twin grain boundaries have been calculated. For the very small $(00 \cdot 1)$ surface a $2 \times 2$ supercell has been used in order to have access to sufficiently low interfacial dopant ion concentrations. Table 1 gives the results obtained in the present study compared to density functional theory (DFT) results ${ }^{27}$ as well as experimental results on samples of sapphire. ${ }^{28,29}$ As can be seen, the surfaces predicted to be the most stable are the basal plane $(00 \cdot 1)$, the prismatic plane $(10 \cdot 0)$ as well as the rhombohedral $(01 \cdot 2)$ surface. The computed surface energies agree reasonably well with those obtained by Marmier and Parker ${ }^{27}$ for non-hydroxylated surfaces, differences being most likely due to limitations inherent to both simulation approaches, such as the system size or the use of interatomic potentials. The agreement with experimental data is also quite good, especially at high temperatures where in exper- 
Table 1

Calculated surface and grain boundary energies $\gamma$ and relative energies $\gamma_{r e l}=\gamma_{\mathrm{hk} \cdot \mathrm{m}} / \gamma_{00 \cdot 1}$ for undoped alumina compared to density functional theory (DFT) results ${ }^{27}$ and experimental data. ${ }^{28,29}$ Grain boundaries are further characterized by their $\Sigma$ value.

\begin{tabular}{|c|c|c|c|c|c|c|c|c|}
\hline \multirow[t]{4}{*}{$(\mathrm{h} \mathrm{k} \cdot \mathrm{m})$} & \multicolumn{6}{|l|}{ Surfaces } & \multirow{3}{*}{\multicolumn{2}{|c|}{$\begin{array}{l}\text { Grain boundaries } \\
\text { Simulation } \\
\text { This study }\end{array}$}} \\
\hline & \multicolumn{3}{|l|}{ Simulation } & \multicolumn{3}{|c|}{ Experiment } & & \\
\hline & \multicolumn{2}{|l|}{ This study } & \multirow{2}{*}{$\begin{array}{l}\mathrm{DFT}^{27} \\
\gamma_{\text {rel }}\end{array}$} & \multirow{2}{*}{$\begin{array}{l}1873 \mathrm{~K}^{28} \\
\gamma_{\mathrm{rel}}\end{array}$} & \multirow{2}{*}{$\begin{array}{l}1873 \mathrm{~K}^{29} \\
\gamma_{\text {rel }}\end{array}$} & \multirow{2}{*}{$\begin{array}{l}2073 \mathrm{~K}^{28} \\
\gamma_{\text {rel }}\end{array}$} & & \\
\hline & $\gamma\left(\mathrm{Jm}^{-2}\right)$ & $\gamma_{r e l}$ & & & & & $\Sigma$ & $\gamma\left(\mathrm{Jm}^{-2}\right)$ \\
\hline$(00 \cdot 1)$ & 2.987 & 1.000 & 1.000 & 1.000 & 1.000 & 1.000 & 3 & 2.66 \\
\hline$(01 \cdot 2)$ & 2.615 & 0.875 & 1.030 & & & & 7 & 0.27 \\
\hline$(10 \cdot 0)$ & 2.885 & 0.966 & 1.293 & $>1.008$ & $>1.16$ & $>1.115$ & 3 & 0.50 \\
\hline$(10 \cdot 1)$ & 3.674 & 1.230 & 1.298 & 0.955 & $>1.12$ & 1.052 & 11 & 1.88 \\
\hline$(11 \cdot 0)$ & 3.023 & 1.012 & 1.182 & 0.987 & $\approx 1.085$ & 1.071 & & \\
\hline$(11 \cdot 0)$ & 3.480 & 1.165 & & & & & 93 & 2.87 \\
\hline$(11 \cdot 2)$ & 3.437 & 1.151 & & & & & 7 & 2.85 \\
\hline$(11 \cdot 3)$ & 3.204 & 1.073 & 1.136 & $>0.970$ & $\approx 1.08$ & 1.037 & 13 & 2.42 \\
\hline$(22 \cdot 3)$ & 3.178 & 1.064 & 1.399 & & & & 43 & 2.95 \\
\hline
\end{tabular}

iment surfaces should be dehydroxylated, thus comparing better to the surfaces calculated here.

The calculated equilibrium morphology shown in Fig. 2 is dominated by $(01 \cdot 2),(10 \cdot 0)$ and $(00 \cdot 1)$ facets. In the equilibrium morphology reported by Kitayama and Glaeser $^{28}(01 \cdot 2)$ and $(00 \cdot 1)$ facets are dominant as well, the $(10 \cdot 0)$ surface on the other hand is not observed and is replaced by $(10 \cdot 1)$ facets. It should be noted however these morphologies were obtained in the presence of non-negligible amounts of impurity elements $\left(\mathrm{Si}^{4+} \sim 15 \mathrm{ppm}, \mathrm{Na}^{+} \sim 7 \mathrm{ppm}, \mathrm{Mg}^{2+} \sim 6 \mathrm{ppm}\right),{ }^{28}$ which even at these concentrations are likely to alter the equilibrium morphology as shown previously for 10 ppm Y doping. ${ }^{6}$

Some of the predicted atomic surface structures are shown in Fig. 3a) (see Supporting Information Fig. S1 for all structures).

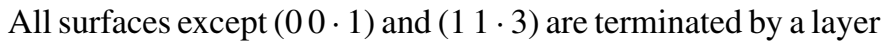

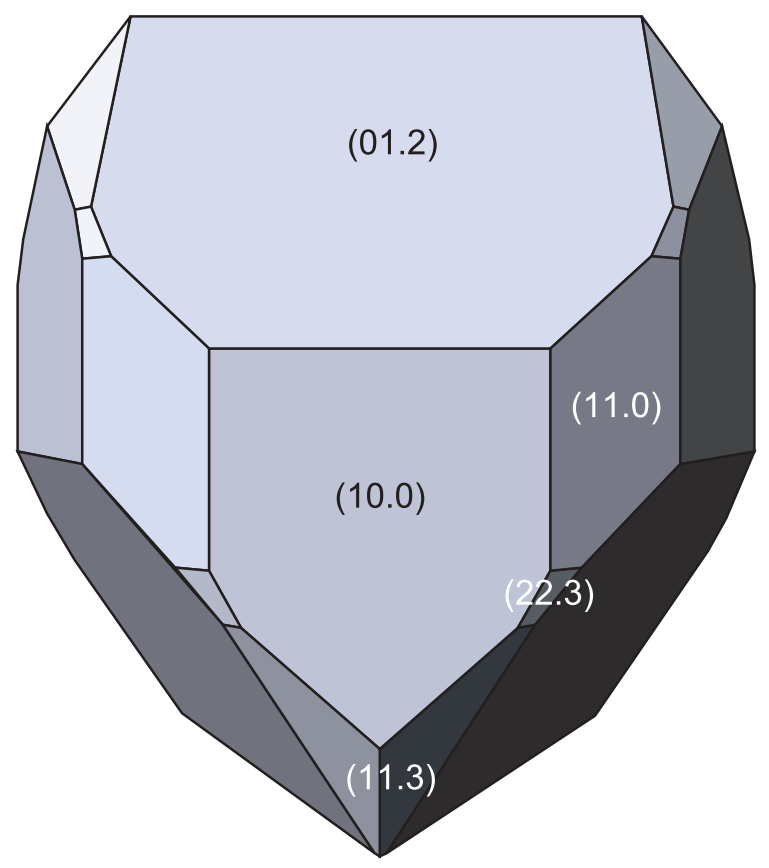

Fig. 2. Calculated equilibrium morphology of undoped $\alpha-\mathrm{Al}_{2} \mathrm{O}_{3}$. of oxygen atoms, which is in agreement with available previous simulation ${ }^{27}$ and experimental ${ }^{30,31}$ studies. It is interesting to note that while low index surfaces exhibit a highly regular structure, higher index surfaces show a tendency to become facetted.

Interfacial energies for undoped mirror twin boundaries are also given in Table 1 . It should be noted that the $(11 \cdot 0)$ plane is a mirror plane in the $\alpha$-alumina structure, its mirror twin boundary thus being equivalent to the bulk, which is why it is not being considered. The computed grain boundary energies are of the same order as previously calculated values for different $(00 \cdot 1)$ twist boundaries $\left(2.8-3.2 \mathrm{~J} / \mathrm{m}^{2}\right){ }^{32}$ These grain boundary energies may be slightly overestimated because only perfect half-crystals are considered, whereas in reality point defects or dislocations may decrease the interfacial energy. ${ }^{33}$ The predicted atomic structures of grain boundaries (some shown in Fig. 3b; see also

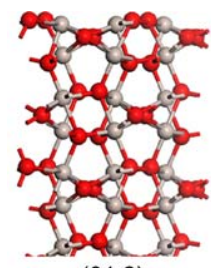

(01.2)

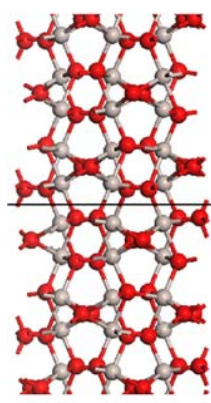

(01.2)

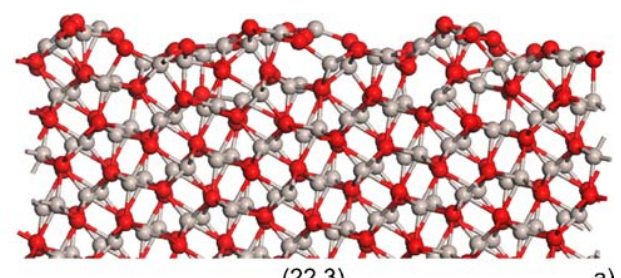

(22.3) a)

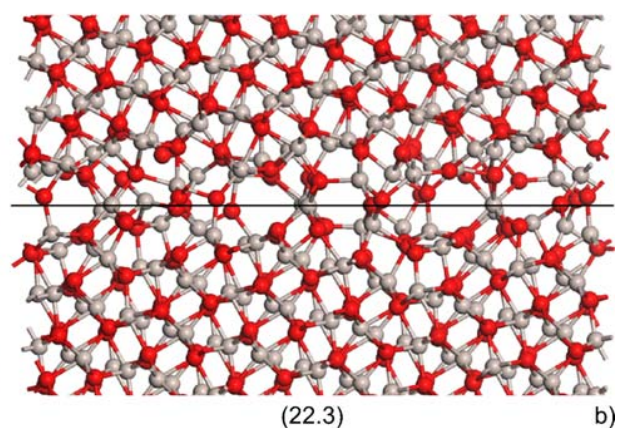

Fig. 3. Predicted undoped (a) surface and (b) grain boundary structures for a highly symmetric $\left(\begin{array}{ll}0 & 1 \cdot 2)\end{array}\right)$ and more general $(22 \cdot 3)$ case $(\mathrm{Al}=$ grey and $\mathrm{O}=$ red $)$. (For interpretation of the references to color in text, the reader is referred to the web version of the article.) 


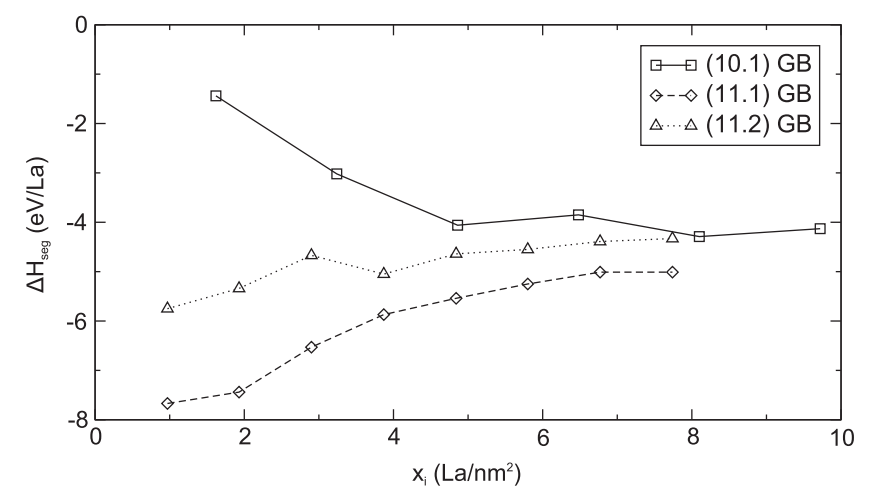

Fig. 4. Segregation energy vs. interface concentration at each concentration curves for the lowest energy configurations depicting the three typical behaviors for La doped grain boundaries: $(10 \cdot 1)$ decrease with multiple minima, $(11 \cdot 0)$ increase without minima, $\left(\begin{array}{ll}1 & 1 \cdot 2)\end{array}\right)$ increase with minimum.

Supporting Information Fig. S2 for all structures) agree well with available experimental high resolution electron microscope (HRTEM) images recorded for undoped alumina bicrystals ${ }^{19}$ as shown in Ref. 6. It can be seen that for low $\Sigma$ boundaries the boundary plane is usually not very marked since the deviation from the perfect crystal structure is small. For higher $\Sigma$ boundaries the boundary plane has a tendency to appear curved and contain voids, which is expected to favor segregation by more efficient accommodation of misfit stress induced by oversized dopant ions. Deviations from the bulk structure (grain boundary width) also extend much further from the grain boundary plane for these interfaces.

\subsection{Lanthanum segregation}

Lanthanum is the biggest dopant considered in this study (ionic radius in a six-fold coordinated environment: $1.03 \AA$, Ref. 34). The stress field around substitutional La dopant ions in the bulk is likely to be high and the bulk solubility consequently very low (ionic radius of $\mathrm{Al}$ in six-fold coordination: $0.54 \AA$, Ref. 34). Indeed the bulk solubility is below the resolution limit of most experimental methods, the exact value being unknown although it has been reported to be lower than $80 \mathrm{ppm} .{ }^{1}$ Due to their size, La dopant ions are expected to segregate stronger to interfaces than $\mathrm{Y}$ ions ${ }^{6}$ (ionic radius for six-fold coordination: $0.90 \AA$, Ref. 34). This is confirmed by the present calculations, which give surface $\Delta H_{\text {seg }}$ between -10 and $-2 \mathrm{eV}$ (Y: -6 to $-2 \mathrm{eV}$, Ref. 6) and grain boundary $\Delta H_{\text {seg }}$ in the range -8 to $-1 \mathrm{eV}$ (Y: -5.5 to $-0.5 \mathrm{eV}$, Ref. 6). The results also qualitatively agree with DFT calculations, where $\Delta H_{\text {seg }}$ of $-1.56 \mathrm{eV}$ for $3.3 \mathrm{La} / \mathrm{nm}^{2}$ were reported for the $\Sigma 3(10 \cdot 0) \mathrm{GB},{ }^{35}$ which compares well with $-1.89 \mathrm{eV}$ for $3.4 \mathrm{La} / \mathrm{nm}^{2}$ calculated here. Another study reported $\Delta H_{\text {seg }}$ of $-2.63 \mathrm{eV}$ for $4.2 \mathrm{La} / \mathrm{nm}^{2}$ at the $\Sigma 7(-10 \cdot 2) \mathrm{GB},{ }^{36}$ which again compares reasonably well with $-2.34 \mathrm{eV}$ for $4.3 \mathrm{La} / \mathrm{nm}^{2}$ found in the present study. Contrary to $\mathrm{Y}$, most $\Delta H_{\text {seg }}\left(x_{i}\right)$ curves for La do not show a minimum but increase with increasing dopant content for both surfaces and high energy grain boundaries (indicated with dashes in Table 2,

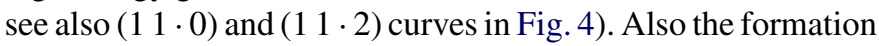

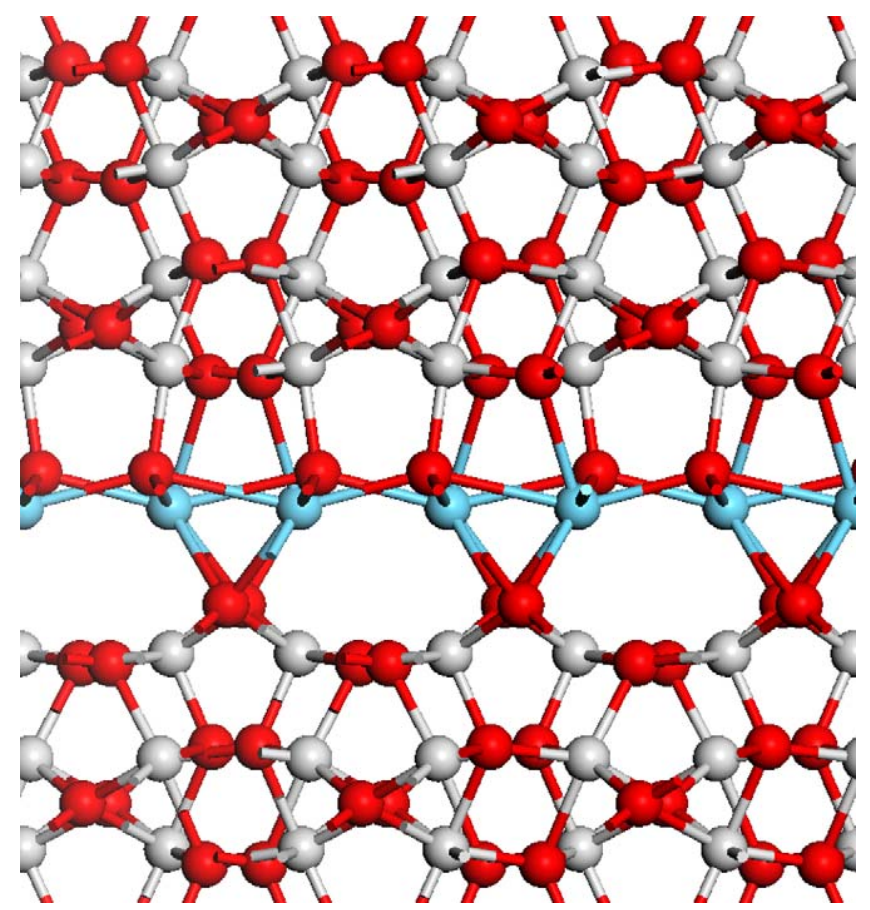

Fig. 5. Calculated $\Sigma 7(01.2)$ grain boundary structure for $\Gamma_{\mathrm{La}}=8.55 \mathrm{~nm}^{-2}$ showing the formation of a regular La pattern at the interface. Color code: $\mathrm{Al}=$ grey, $\mathrm{O}=$ red, $\mathrm{La}=$ blue. (For interpretation of the references to color in text, the reader is referred to the web version of the article.)

of regular columns and patterns as reported for $\mathrm{Y}^{6,21}$ seems to be absent for La.

A very interesting behavior is however exhibited by low energy grain boundaries $(\Sigma 3(00 \cdot 1), \Sigma 7(01 \cdot 2), \Sigma 3(10 \cdot 0)$, $\Sigma 11(10 \cdot 1))$. Although in general a minimum cannot be clearly observed, the segregation energy decreases with increasing dopant concentration until about $8-10 \mathrm{La} / \mathrm{nm}^{2}$ (see for example the $(10 \cdot 1)$ curve in Fig. 4). For higher concentrations the segregation enthalpy stays more or less constant. This change in behavior seems to coincide with the complete substitution of Al by La in a layer at the grain boundary. For the $\Sigma 7\left(\begin{array}{ll}0 & 1 \cdot 2)\end{array}\right.$ grain boundary this behavior is most marked, with a minimum at $8.55 \mathrm{La} / \mathrm{nm}^{2}$, which corresponds to such a La layer (Fig. 5).

To check if these La layers have structural similarities with possible precipitates, coordination numbers and nearest neighbor distances in the selected surfaces and grain boundaries were compared to those in $\mathrm{La}_{2} \mathrm{O}_{3}, \mathrm{LaAlO}_{3}$ and $\mathrm{LaAl}_{11} \mathrm{O}_{18}$ crystals (see Supporting Information Table S1). No clear trend could be detected, the La chemical environment being intermediate to these three phases.

The question whether or not a second phase layer forms at the interface was for instance put forward by Bruley et al. ${ }^{37}$ The present results seem to indicate that layer formation is not dictated by a close match with a precipitate crystal phase but is rather controlled by the underlying grain boundary structure (low energy grain boundaries). This finding supports the fact that, depending on the ease of dopant accommodation, certain grain boundaries are more prone to complexion than others and that - given sufficient time for the complexion transformations 
Table 2

Minimum energy dopant ion concentration $\left(\Gamma_{\text {Emin }}\right)$ and estimated solubility $\left(\Gamma_{e q}\right)$ for different La doped $\alpha$-alumina surfaces and mirror twin grain boundaries. For interfaces with a dash, a continuous increase in energy is observed, for those marked with a * the curve decreased and flattened out but no clear minimum in energy was discernable.

\begin{tabular}{|c|c|c|c|c|c|}
\hline \multirow[t]{2}{*}{$(\mathrm{h} \mathrm{k} \cdot \mathrm{m})$} & \multicolumn{2}{|l|}{ Surfaces } & \multicolumn{3}{|c|}{ Grain boundaries } \\
\hline & $\Gamma_{\text {Emin }}\left[\mathrm{nm}^{-2}\right]$ & $\bar{\Gamma} \Gamma_{e q}\left[\mathrm{~nm}^{-2}\right]$ & $\bar{\Sigma}$ & $\Gamma_{E \operatorname{Emin}}\left[\mathrm{nm}^{-2}\right]$ & $\Gamma_{e q}\left[\mathrm{~nm}^{-2}\right]$ \\
\hline$(00 \cdot 1)$ & - & 0.00 & 3 & $*$ & 0.00 \\
\hline$\left(\begin{array}{lll}0 & 1 & \cdot\end{array}\right)$ & 2.85 & 4.08 & 7 & 8.55 & 0.00 \\
\hline$(11 \cdot 2)$ & - & 9.30 & 7 & - & 1.76 \\
\hline$\left(\begin{array}{lll}1 & 1 & \cdot 3)\end{array}\right.$ & 3.42 & 12.17 & 13 & 1.71 & 5.04 \\
\hline$(11 \cdot 0)$ & 2.95 & 5.70 & & & \\
\hline$(10 \cdot 0)$ & - & 9.26 & 3 & $*$ & 0.00 \\
\hline$(10 \cdot 1)$ & - & 8.80 & 11 & $*$ & 0.00 \\
\hline$(22 \cdot 3)$ & - & 8.33 & 43 & - & 2.12 \\
\hline$(11 \cdot 0)$ & - & 11.02 & 93 & - & 8.70 \\
\hline Avg & & 7.63 & & & 2.20 \\
\hline
\end{tabular}

to occur - dopant ions will control the atomic structure in the grain boundary region. ${ }^{3}$

In order to characterize the contribution of the various grain boundaries to the total amount of dopant ions dissolved at grain boundaries, the grain boundary solubility limit for each interface was defined as the concentration at which $\Delta H_{\text {sol }}$ calculated according to Eq. (2) is equal to zero. As can be seen from the values reported in Table 2, the average solubility limit for surfaces and grain boundaries is $7.63 \mathrm{La} / \mathrm{nm}^{2}$ and $2.20 \mathrm{La} / \mathrm{nm}^{2}$ respectively. This sample contains however a significant proportion of highly special low $\Sigma$ boundaries, which in real $\alpha$-alumina microstructures constitute only a very small fraction of the grain boundary population. ${ }^{38-41}$ An average taken only over high$\Sigma$, high-energy boundaries, which should have more general character, is therefore likely to result in a better description of experiment. The average value of $5.29 \mathrm{La} / \mathrm{nm}^{2}$ over the $\Sigma 93$ $(11 \cdot 0), \Sigma 13(11 \cdot 3)$ and $\Sigma 43(22 \cdot 3)$ boundaries shows that indeed these more general boundaries can accommodate a higher dopant content, as suggested by their more open structure (see Supporting Information Table S2 for coordinative environment). Surprisingly these solubility limits are higher than the predicted average solubility for $\mathrm{Y}\left(3.29 \mathrm{Y} / \mathrm{nm}^{2}\right.$ for surfaces and 2.09 Y/nm ${ }^{2}$ for all and 3.15 Y/nm² for high energy $\mathrm{GBs}^{6}$ ) despite the less favorable ionic size. Experimental energy-dispersive $\mathrm{X}$ ray measurements ${ }^{37}$ indicate $4.5 \pm 0.9 \mathrm{La} / \mathrm{nm}^{2}$ in a La saturated $\alpha$-alumina and $4.4 \pm 1.5 \mathrm{Y} / \mathrm{nm}^{2}$ in a Y saturated $\alpha$-alumina. A notable difference between experiments and calculations is that solubility limits for La and Y are very similar in experiments, whereas calculations predict a much higher La solubility. This may be due to the limited number of grain boundaries investigated in our simulations as well as the effect of impurities in the experimental data. Despite these discrepancies, the agreement between experimental and calculated solubilities is quite good, the calculated values being within the experimental spread.

Based on these results it is possible to explain experimental observations for the effect of $\mathrm{Y}$ and La dopants. Both dopants are known to decrease grain growth during sintering ${ }^{42,43}$ and increase the high-temperature creep resistance ${ }^{44-49}$ of $\alpha$ alumina. Grain boundary segregation rather than second phase precipitation is the cause of these effects, as they occur below the solubility limit. ${ }^{43,46,47,50}$ Initial suggestions that La dopants promote the formation of low-energy, low- $\Sigma$ boundaries could not be substantiated ${ }^{38}$ and the prevalent opinion in recent literature is that both dopants reduce grain boundary diffusion ${ }^{21,38,47,48}$ and grain boundary dislocation climb/slide ${ }^{33,49}$ due to site blocking. Due to the higher segregation energy calculated here and elsewhere ${ }^{35,36}$ the interface concentration of La at the same overall dopant concentration and grain size is expected to be higher than for Y. Also the larger La ion should intuitively be more effective at blocking diffusion paths and dislocation motion. Experimental studies however indicate that below the solubility limit and at the same dopant concentration and sintering conditions, La and Y doped samples have approximately the same grain size. ${ }^{43,46,47}$ The effect on creep resistance is also reported to be either very similar ${ }^{45,46}$ or even less for La than for Y.47 From the present results two possible indications as to why La is not more effective than Y can be gained. Firstly the tendency of La to form a continuous layer at low energy grain boundaries rather than hard to disrupt regular low energy columns and patterns as reported for $\mathrm{Y}^{6,21}$ might make La dopants less effective in reducing grain boundary diffusion. Secondly the lower La-O coordination number $(<6)$ (see Supplementary Information, Table S1) compared to the one for Y-O of about $7^{6,21}$ is likely to increase the mobility of La dopants in all grain boundaries thus decreasing their efficiency in reducing grain boundary diffusion and dislocation mobility.

\subsection{Gadolinium and ytterbium segregation}

Two other lanthanide dopants, studied experimentally in alumina ceramics are Gadolinium $(\mathrm{Gd})$ and Ytterbium $(\mathrm{Yb}){ }^{5}$ Both have smaller ionic radii than Lanthanum $(\mathrm{Gd}=0.94 \AA$, $\mathrm{Yb}=0.87 \AA$, Ref. 34), Yb being even smaller than Y. The expected segregation and bulk solubility for Gd is thus intermediate to La and Y, while Yb should be the most soluble. Predicted surface $\Delta H_{\text {seg }}$ are for $\mathrm{Gd}(-7$ to $-2 \mathrm{eV})$ and $\mathrm{Yb}(-6$ to $-1 \mathrm{eV})$ while grain boundary $\Delta H_{\text {seg }}$ varied between -6 and $-1 \mathrm{eV}$ for both dopants. Comparing these results to the larger La ion, surfaces segregation shows a clear dependence on the ionic radius. While both dopants have a lower tendency for grain boundary 
segregation than La, there is no clear size effect between Gd and $\mathrm{Yb}$.

The predicted average solubility (Table 3) for surfaces is $4.54 \mathrm{Gd} / \mathrm{nm}^{2}$ and $>4.86 \mathrm{Yb} / \mathrm{nm}^{2}$. The solubility limit was not reached with the maximum number of $\mathrm{Yb}$ dopants for the $(22 \cdot 3)$ surface, therefore only a lower bound can be given. The predicted average solubility over all grain boundaries is $2.15 \mathrm{Gd} / \mathrm{nm}^{2}$ and $2.54 \mathrm{Yb} / \mathrm{nm}^{2}$ or $4.96 \mathrm{Gd} / \mathrm{nm}^{2}$ and $5.30 \mathrm{Yb} / \mathrm{nm}^{2}$ if only the subset of high- $\Sigma$, high-energy boundaries $((\Sigma 93$ $(11 \cdot 0), \Sigma 13(11 \cdot 3)$ and $\Sigma 43(22 \cdot 3))$ is considered. As expected, the smaller $\mathrm{Yb}$ has a higher solubility than $\mathrm{Gd}$. The dopant/Al ratio in a $1 \mathrm{~nm}$ thick segregation layer was determined experimentally to be $0.11 \pm 0.02$ for both dopants. ${ }^{5}$ This would correspond to a solubility of $2.75 \mathrm{~nm}^{-2}$ for a GB with segregation layers in each half-crystal, which compares reasonably well with the solubilities predicted in the present study.

It is interesting to note that minimum energy interfacial coverages $\Gamma_{\text {Emin }}$ (Table 3 ) are not observed for the same surfaces for both dopants $\left(\left(\begin{array}{lll}1 & 1 \cdot 2)\end{array}\right)\right.$ and $(10 \cdot 1)$ respectively). This indicates surface segregation to be governed not only by dopants ionic size but also the interaction of the dopants with their environment, i.e. complexation. For Yb dopants an additional GB shows a $\Gamma_{\text {Emin }}$ compared to $\mathrm{Gd}$, indicating that the smaller dopant is more easily accommodated. The formation of patterns seems to be absent for $\mathrm{Gd}$ and $\mathrm{Yb}$ as it was for La. However for both dopants the same minimum energy configuration at $8.55 \mathrm{cat} / \mathrm{nm}^{2}$ on the $\Sigma 7(01 \cdot 2) \mathrm{GB}$, corresponding to a dopant layer formation as shown for La in Fig. 5 is observed. Despite this similarity, La is much more soluble in surfaces than both $\mathrm{Gd}$ and $\mathrm{Yb}$, whereas for grain boundaries $\mathrm{Gd}$ is the least soluble dopant followed by $\mathrm{La}$ and $\mathrm{Yb}$. Again the ionic size does not seem to be the only parameter controlling solubility, the stability of the stable dopant oxide phase is likely to be playing an important role as well.

$\mathrm{Gd}$ is predicted to have a lower GB concentration than $\mathrm{La}$ and being smaller is expected to be less efficient at blocking diffusion sites and dislocation motion in the boundary. Yb on the other hand has a higher concentration than La but is significantly smaller. Concentration and site blocking effects will therefore counterbalance each other, making it difficult to conclude on the expected efficiency of $\mathrm{Yb}$ compared to $\mathrm{La}$.

\subsection{Magnesium segregation}

Magnesium is the only aliovalent dopant $\left(\mathrm{Mg}^{2+}\right.$ vs. $\left.\mathrm{Al}^{3+}\right)$ considered in this study. The net charge is kept neutral by creating a charge compensating oxygen vacancy for every two $\mathrm{Mg}$ ions substituted for $\mathrm{Al}$. The size of $\mathrm{Mg}^{2+}$ in six fold coordination ( $0.72 \AA$, Ref. 34) albeit smaller than lanthanides is still larger than the aluminum ion. Grain boundary ${ }^{51-53}$ and surface ${ }^{54-57}$ segregation of $\mathrm{Mg}$ still occurs, the extent being less pronounced than for the larger elements considered above. Experimental values for the $\mathrm{Mg}$ bulk solubility in $\alpha$-alumina vary substantially; the most recent value found in the literature $\left(132 \pm 11 \mathrm{ppm}\right.$ at $\left.1600^{\circ} \mathrm{C}\right)$ was measured using a wavelength dispersive spectroscopy, ${ }^{51}$ whereas Roy and Coble ${ }^{58}$ reported a solubility limit of $300 \mathrm{ppm}$ at $1630^{\circ} \mathrm{C}$ based on spectrochemical analysis.

The calculated $\Delta H_{\text {seg }}$ for magnesium lie between $-5.5 \mathrm{eV}$ and $-2.0 \mathrm{eV}$ for surfaces and between $-4.0 \mathrm{eV}$ and $-1.5 \mathrm{eV}$ for grain boundaries. These energies are of a lesser magnitude than those of lanthanide dopants, indicating indeed less pronounced segregation.

Energies for configurations with the same dopant concentration have a much more continuous spectrum than for the lanthanide elements. This is due to a rather weak binding between the vacancies and dopants, allowing for many possible arrangements within the segregation layer. As a result no particular dopant/vacancy configuration with a much lower energy exists and diffusive interchange between different vacancy and $\mathrm{Mg}$ sites should be rapid. $\mathrm{Mg}$ doping will therefore result in a high concentration of mobile ions in the segregation layer of about $\sim 5 \AA$ around the interface. This is consistent with the fact that $\mathrm{Mg}$ was shown to increases both grain growth and densification rate during the early stages of sintering. ${ }^{59}$ The former is likely due to increased surface diffusion, ${ }^{59,60}$ whereas the latter is attributed to an increase in grain boundary diffusion, 59 which would also explain the increase in creep rate at high temperatures. .8,61 $^{48}$

Most $\Delta H_{s e g}\left(x_{i}\right)$ curves continually become more positive with increasing dopant concentration (dashes in Table 4), with the exception of the $\Sigma 3(10 \cdot 0)$ and the $\Sigma 11(10 \cdot 1)$ grain boundaries (Table 4). The coordination of the $\mathrm{Mg}$ ions of these two minima was compared to possible $\mathrm{MgO}$ and $\mathrm{MgAl}_{2} \mathrm{O}_{4}$ precipitates (see Supporting Information Table S3). Just as for La the minimum energy structures, (complexions) do not seem to closely resemble any of the possible precipitates, the $\mathrm{Mg}-\mathrm{O}$ environment being quite close to $\mathrm{MgO}$, while the $\mathrm{Mg}-\mathrm{Mg}$ environment is closer to $\mathrm{MgAl}_{2} \mathrm{O}_{4}$. It is however interesting to note that the calculated $\mathrm{Mg}-\mathrm{O}$ coordination number is lower than the one for $\mathrm{La}-\mathrm{O}$, which will further contribute to a higher mobility compared to La dopants and thus to higher diffusion rates. $^{21}$

The average predicted equilibrium solubility given in Table 4 is $4.32 \mathrm{Mg} / \mathrm{nm}^{2}$ for surfaces and $2.18 \mathrm{Mg} / \mathrm{nm}^{2}$ for grain boundaries $\left(2.61 \mathrm{Mg} / \mathrm{nm}^{2}\right.$ for high-energy, high- $\Sigma$ grain boundaries - see Supporting Information Table S4 for coordinative environment). This is considerably lower than the values calculated for La but is close to the predicted solubility for Y. ${ }^{6}$ There is agreement with the fact that high energy boundaries more easily accommodate dopants in various complexions, whereas low energy boundaries are more prone to second phase precipitation. ${ }^{3}$ Solubilities found in the literature are similar with $2-3 \mathrm{Mg} / \mathrm{nm}^{2}$ at $1600{ }^{\circ} \mathrm{C} .{ }^{51} \mathrm{Mg}$ enrichment $\left(x_{i} / x_{b}\right)$ was reported to be 400 within a grain boundary region of $1 \mathrm{~nm}$ in $\mathrm{Mg}$ saturated $\alpha$-alumina. ${ }^{53}$ Depending on whether a bulk saturation concentration of $132 \mathrm{ppm}^{51}$ or $300 \mathrm{ppm}^{58}$ is considered, this would correspond to a grain boundary concentration of $2.5 \mathrm{Mg} / \mathrm{nm}^{2}$ or $5.7 \mathrm{Mg} / \mathrm{nm}^{2}$ respectively. The agreement between predicted and measured grain boundary solubilities is therefore reasonably good when considering again the more general subset of high-energy, high- $\Sigma$ boundaries and the lower bulk solubility. Below the solubility limit these high-energy boundaries thus 
Table 3

Minimum energy interface concentration $\left(\Gamma_{\text {Emin }}\right)$ and equilibrium interface concentration $\left(\Gamma_{e q}\right)$ for Gd and Yb dopants at alumina surfaces and grain boundaries. For interfaces with a dash, a continuous increase in energy is observed, for those marked with a $*$ the curve decreased and flattened out but no clear minimum in energy was discernable.

\begin{tabular}{|c|c|c|c|c|c|c|c|c|c|}
\hline \multirow[t]{3}{*}{$(\mathrm{h} \mathrm{k} \cdot \mathrm{m})$} & \multicolumn{4}{|l|}{ Surfaces } & \multicolumn{5}{|c|}{ Grain boundaries } \\
\hline & \multicolumn{2}{|l|}{$\mathrm{Gd}$} & \multicolumn{2}{|l|}{$\mathrm{Yb}$} & \multirow[t]{2}{*}{$\Sigma$} & \multicolumn{2}{|l|}{$\mathrm{Gd}$} & \multicolumn{2}{|l|}{$\mathrm{Yb}$} \\
\hline & $\Gamma_{E \operatorname{Emin}}\left[\mathrm{nm}^{-2}\right]$ & $\Gamma_{e q}\left[\mathrm{~nm}^{-2}\right]$ & $\Gamma_{E \operatorname{Emin}}\left[\mathrm{nm}^{-2}\right]$ & $\Gamma_{e q}\left[\mathrm{~nm}^{-2}\right]$ & & $\Gamma_{E \operatorname{Emin}}\left[\mathrm{nm}^{-2}\right]$ & $\Gamma_{e q}\left[\mathrm{~nm}^{-2}\right]$ & $\Gamma_{E \operatorname{Emin}}\left[\mathrm{nm}^{-2}\right]$ & $\Gamma_{e q}\left[\mathrm{~nm}^{-2}\right]$ \\
\hline$(00 \cdot 1)$ & - & 0.00 & - & 0.00 & 3 & 5.19 & 0.00 & 5.19 & 0.00 \\
\hline$\left(\begin{array}{lll}0 & 1 & \cdot 2\end{array}\right)$ & 2.85 & 0.00 & 2.85 & 0.00 & 7 & 8.55 & 0.00 & 8.55 & 0.00 \\
\hline$(11 \cdot 2)$ & - & 5.72 & 1.84 & 6.16 & 7 & - & 2.34 & 1.84 & 4.44 \\
\hline$(11 \cdot 3)$ & 2.57 & 3.45 & 2.57 & 3.70 & 13 & - & 6.39 & - & 8.29 \\
\hline$(11 \cdot 0)$ & 2.95 & 4.74 & 2.95 & 4.51 & & & & & \\
\hline$(10 \cdot 0)$ & - & 9.65 & - & 11.16 & 3 & $*$ & 0.00 & 6.82 & 0.00 \\
\hline$(10 \cdot 1)$ & 3.24 & 6.23 & - & 6.33 & 11 & $*$ & 0.00 & $*$ & 0.00 \\
\hline$(22 \cdot 3)$ & - & 4.67 & - & $>4.73$ & 43 & - & 2.40 & - & 0.48 \\
\hline$(11 \cdot 0)$ & - & 6.43 & - & 7.04 & 93 & - & 6.10 & - & 7.13 \\
\hline Avg & & 4.54 & & $>4.86$ & & & 2.15 & & 2.54 \\
\hline
\end{tabular}

lower their relative energy according to Eq. (9), which results in a homogenization of the grain boundary energies.

$\gamma_{\text {doped }} \approx \gamma+\Gamma \Delta H_{\text {seg }}$

This elimination of high energy boundaries by $\mathrm{Mg}$ doping was also observed in experiment ${ }^{62}$ and may be one of the reasons for the suppression of abnormal grain growth, which is the main effect of $\mathrm{Mg}$ on the microstructure. ${ }^{59}$ Another reason for abnormal grain growth suppression by $\mathrm{Mg}$ is solute drag due to the segregated dopants/vacancies and above the solubility limit also grain boundary pinning by precipitates. In addition pore attachment to grain boundaries is enhanced by increased interface diffusion rates, further inhibiting abnormal grain growth. ${ }^{59}$

\subsection{Nominal solubility of dopants in a ceramic microstructure}

As discussed above, highly special low $\Sigma$, low energy grain boundaries represent only a small percentage of the total GB population in real microstructures. ${ }^{38-41}$ Therefore for the calculation of nominal solubilities representative of real microstructures, only the three high-energy, high- $\Sigma$ grain boundaries $\Sigma 93(11 \cdot 0), \Sigma 13(11 \cdot 3)$ and $\Sigma 43(22 \cdot 3)$ were considered. To limit the number of possible dopant configurations per unit cell, segregation was assumed to be limited to the 12 lowest energy sites for $\mathrm{Y}$ and $\mathrm{Mg}$, and the 18 lowest energy sites for oxygen vacancies. As $\Gamma_{\text {sat }}$ is higher for La the 30 lowest energy sites were considered. The temperature was considered to be $1600{ }^{\circ} \mathrm{C}$ for all calculations.

\subsubsection{Yttrium}

As can be seen from the results for $\mathrm{Y}$ segregation at the $\Sigma 93(11 \cdot 0)$ grain boundary shown in Fig. 6a), the Monte Carlo results closely follow the minimum of the energy minimization results at all relevant concentrations. The plateau at the very left is due to the lower limit of achievable concentrations as represented by a single dopant per simulation cell. The resulting curve (Fig. 6b) of the grain boundary cationic ratio as a function of the bulk cationic ratio shows that at low bulk concentrations, the grain boundary concentration changes only very little, whereas at high dopant concentration, which are most relevant in experiments, a rapid increase in interfacial dopant concentrations is observed.

The predicted nominal Y solubility as a function of grain size, assuming a bulk solubility of $10 \mathrm{ppm},{ }^{63,64}$ is plotted in Fig. 7, along with various experimental literature values. ${ }^{41,65-68}$ The

Table 4

Minimum energy dopant ion concentration $\left(\Gamma_{E m i n}\right)$ and estimated solubility $\left(\Gamma_{e q}\right)$ for different Mg doped $\alpha$-alumina surfaces and mirror twin grain boundaries. For interfaces with a dash, a continuous increase in energy is observed, for those marked with a * the curve decreased and flattened out but no clear minimum in energy was discernable.

\begin{tabular}{|c|c|c|c|c|c|}
\hline \multirow[t]{2}{*}{$(\mathrm{hk} \cdot \mathrm{m})$} & \multicolumn{2}{|l|}{ Surfaces } & \multicolumn{3}{|c|}{ Grain boundaries } \\
\hline & $\Gamma_{\text {Emin }}\left[\mathrm{nm}^{-2}\right]$ & $\Gamma_{e q}\left[\mathrm{~nm}^{-2}\right]$ & $\bar{\Sigma}$ & $\Gamma_{\text {Emin }}\left[\mathrm{nm}^{-2}\right]$ & $\Gamma_{e q}\left[\mathrm{~nm}^{-2}\right]$ \\
\hline$(00 \cdot 1)$ & $*$ & 0.00 & 3 & - & 7.45 \\
\hline$\left(\begin{array}{lll}0 & 1 & \cdot 2\end{array}\right)$ & - & 0.00 & 7 & $*$ & 0.00 \\
\hline$(11 \cdot 3)$ & - & 4.78 & 13 & $*$ & 0.00 \\
\hline$(11 \cdot 0)$ & - & 5.80 & & & \\
\hline$(10 \cdot 0)$ & - & 0.00 & 3 & 5.11 & 0.00 \\
\hline$(10 \cdot 1)$ & - & 11.11 & 11 & 2.85 & 0.00 \\
\hline$(22 \cdot 3)$ & - & 3.66 & 43 & - & 2.90 \\
\hline$(111 \cdot 0)$ & - & 9.21 & 93 & - & 4.92 \\
\hline Avg & & 4.32 & & & 2.18 \\
\hline
\end{tabular}



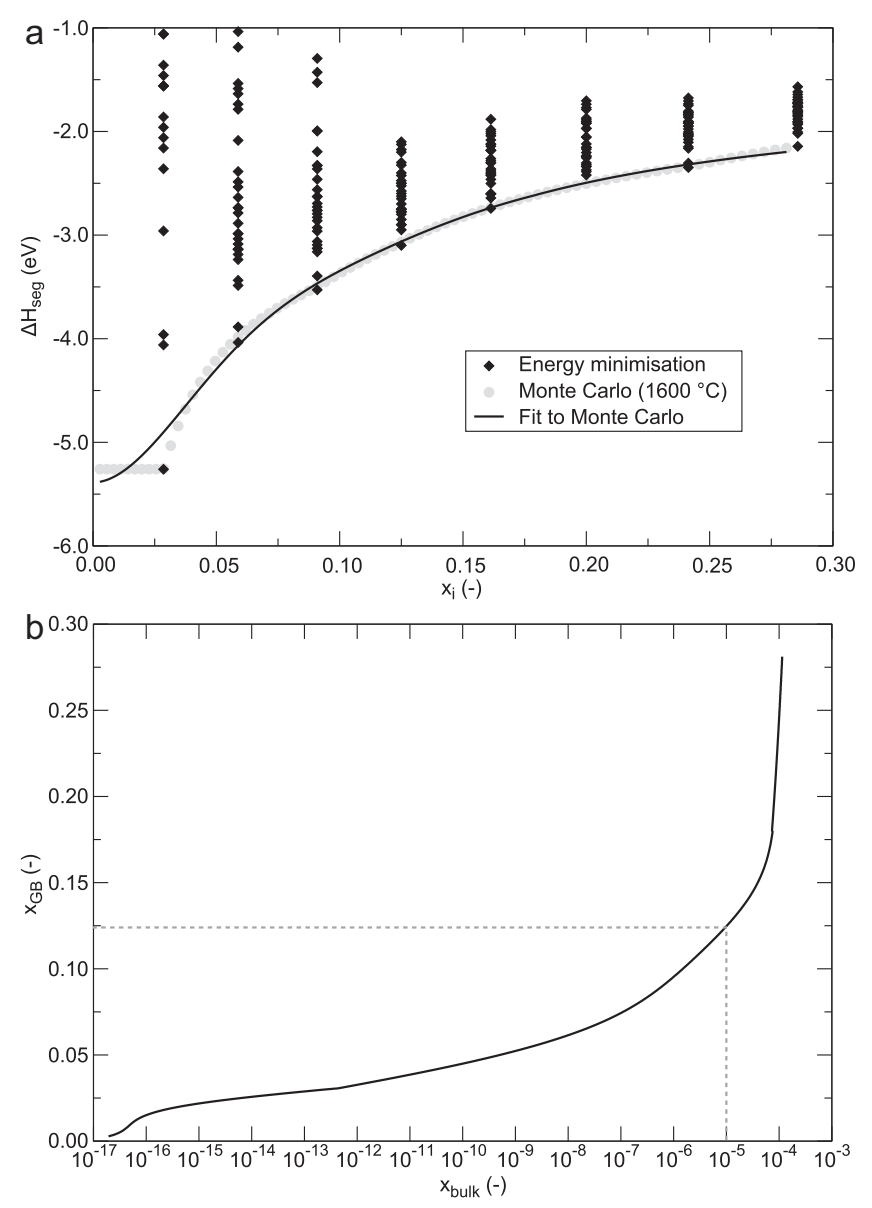

Fig. 6. (a) Energy minimization and Monte Carlo results as well as the smooth fit to the Monte Carlo results for Y dopants at the $\Sigma 93(11 \cdot 0)$ grain boundary and (b) calculated $x_{G B}$ vs. $x_{\text {bulk }}$ curve for $\mathrm{Y}$ dopants at the $\Sigma 93(11 \cdot 0)$ grain boundary. The grain boundary concentration in equilibrium with the bulk solubility limit $\left(x_{b}=10^{-5}\right)$ is about 0.125 .

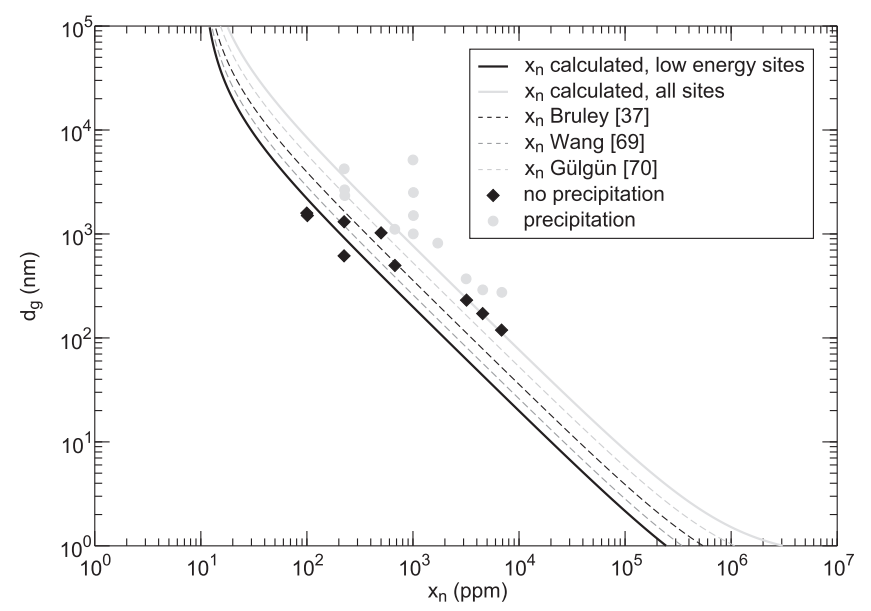

Fig. 7. Calculated nominal Y solubility limit for different grain sizes. The solid black and grey curves were calculated considering only the 12 lowest energy segregation sites or all sites within $3 \AA$ of the boundary respectively. The broken lines correspond to various solubility limits reported in the literature, ${ }^{37,75,76}$ whereas the grey and black data points correspond to experimental observations ${ }^{41,65-68}$ indicating whether precipitation was observed or not for a given grain size and dopant concentration. first observation is that the calculated nominal solubility (solid black curve) is slightly lower than the experimentally observed values. Besides errors on the calculated segregation energies, a possible source for this deviation could be the grain shape in real microstructures, which will neither be truncated octahedrons nor mono-disperse, leading to slight differences in specific grain boundary area. Furthermore sintering temperatures, cooling rates and impurities influence the solubility limit and may result in differences. The restriction of segregation to the 12 lowest energy sites could be another reason for the low solubility. In order to test this hypothesis all sites within $3 \AA$ of the grain boundary (grain boundary width of $6 \AA$ ) were considered as possible segregation sites. While still only the 12 lowest are significant for the calculation of the mean segregation energy (much higher occupation due to their lower energy) the resulting solubility limit is now above the experimentally observed values (solid grey curve in Fig. 7). This illustrates the importance of these higher energy sites and the problem of overestimating configurational entropy by segregation theories based on sites of equal energy such as the Mackrodt and Tasker theory ${ }^{15}$ (see also Supporting Information S6). Theories based on simple dopant-dopant interactions ${ }^{22}$ are also likely to be inadequate for alumina grain boundaries.

Another interesting observation is that while the present truncated octahedron model predicts an inversely linear dependence of the nominal solubility on the grain size, the experimental observations seem to follow a curve which depends on the grain size to the power of -0.76 . The inverse linearity of the model is due to the dependence of the specific grain boundary area on the grain size. It has to be noted that any other possible grain shape model (i.e. sphere, ellipsoid, or cube) would lead to the same inverse linear dependence. It is possible however that the grain shape and size distribution changes as a function of grain size, leading to a different specific grain boundary area. As experimental data points were collected from several different sources, ${ }^{41,65-68}$ it is also possible that experimental parameters such as impurity level, porosity, sintering temperatures or cooling rates lead to slight variations in solubility.

\subsubsection{Magnesium}

As mentioned above, for $\mathrm{Mg}$ different bulk solubilities were reported. ${ }^{51,58}$ Fig. 8 therefore contains a solubility curve calculated with the lower solubility (132 ppm) reported by Miller et al. ${ }^{51}$ (dashed grey line), as well as one computed using the higher $\left(300 \mathrm{ppm}\right.$ ) bulk solubility by Roy and Coble ${ }^{58}$ (solid black line). Also shown are experimental observations of conditions under which precipitation was or was not observed as reported in various $\mathrm{Mg}$ doped samples. ${ }^{53,60,69-74}$

If compared to the experimental precipitation/no precipitation data, the bulk solubility of $132 \mathrm{ppm}^{51}$ seems to be too low, whereas curves calculated using the value of $300 \mathrm{ppm}^{58}$ seem to result in a better fit. The calculated solubility using this value is slightly higher than experimental observations. Apart from possible differences between calculation and experiment already covered in the discussion of the $Y$ results and the uncertainty on the $\mathrm{Mg}$ bulk solubility there is a further explanation for the predicted high solubility: Eq. (4), which was used for 
Table 5

Grain boundary concentration, enthalpy of segregation and grain boundary energy for the calculated grain boundary solubility limit for Y, La and Mg dopants in the three more general high-energy, high $\Sigma$ boundaries.

\begin{tabular}{|c|c|c|c|c|c|c|c|c|c|c|}
\hline \multirow[t]{2}{*}{ Interface } & \multirow{2}{*}{$\begin{array}{l}\text { Pure } \\
\gamma\left[\mathrm{J} / \mathrm{m}^{2}\right]\end{array}$} & \multicolumn{3}{|l|}{$\mathrm{Y}$} & \multicolumn{3}{|l|}{$\mathrm{La}$} & \multicolumn{3}{|l|}{$\mathrm{Mg}$} \\
\hline & & $\Gamma_{\text {sat }}\left[\mathrm{nm}^{-2}\right]$ & $\Delta H[\mathrm{eV} / \mathrm{cat}]$ & $\gamma\left[\mathrm{J} / \mathrm{m}^{2}\right]$ & $\Gamma_{\text {sat }}\left[\mathrm{nm}^{-2}\right]$ & $\Delta H[\mathrm{eV} / \mathrm{cat}]$ & $\gamma\left[\mathrm{J} / \mathrm{m}^{2}\right]$ & $\Gamma_{\text {sat }}\left[\mathrm{nm}^{-2}\right]$ & $\Delta H[\mathrm{eV} / \mathrm{cat}]$ & $\gamma\left[\mathrm{J} / \mathrm{m}^{2}\right]$ \\
\hline$\Sigma 13(11 \cdot 3)$ & 2.42 & 1.93 & -2.67 & 1.60 & 3.60 & -6.41 & -1.28 & 6.59 & -2.39 & -0.11 \\
\hline$\Sigma 93(11 \cdot 0)$ & 2.87 & 1.29 & -3.07 & 2.24 & 12.19 & -4.90 & -6.70 & 11.57 & -2.62 & -1.98 \\
\hline$\Sigma 43(22 \cdot 3)$ & 2.95 & 4.12 & -2.18 & 1.51 & 2.63 & -5.24 & 0.75 & 3.00 & -3.17 & 1.43 \\
\hline
\end{tabular}

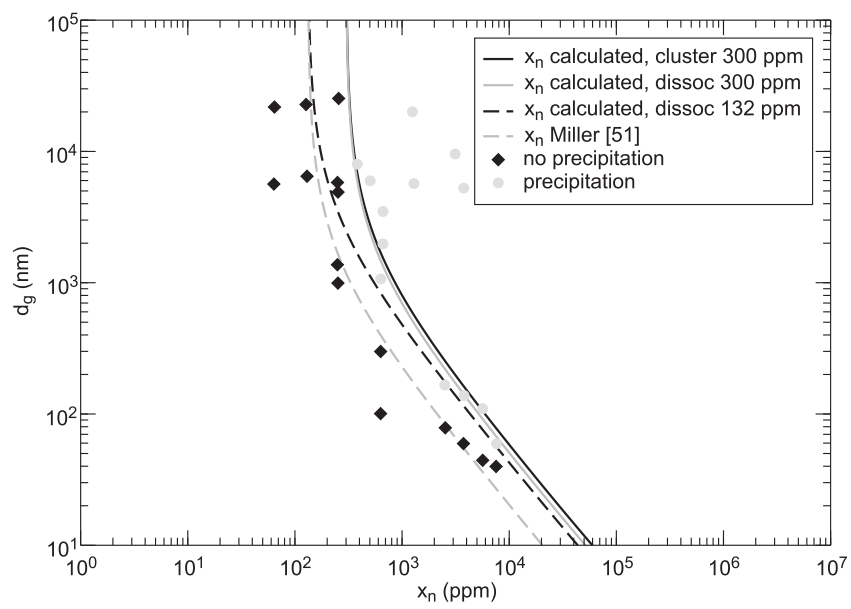

Fig. 8. Calculated nominal $\mathrm{Mg}$ solubility limit for different grain sizes along with experimental values taken from Ref. 53,60,69-74. The black continuous curve was calculated considering the $\mathrm{Mg}-\mathrm{O}_{\mathrm{vac}}-\mathrm{Mg}$ cluster to segregate as one entity. The grey curves were calculated for a completely dissociated $\mathrm{Mg}-\mathrm{O}_{\mathrm{vac}}-\mathrm{Mg}$ cluster. Continuous curves were calculated for a bulk solubility of $300 \mathrm{ppm}$, the dashed line with a bulk solubility of $132 \mathrm{ppm}$.

the calculations has been developed by Mackrodt and Tasker ${ }^{15}$ for the case of isovalent dopants. This formula can also be employed for aliovalent $\mathrm{Mg}$ dopants if the $\mathrm{Mg}-\mathrm{O}_{\mathrm{vac}}-\mathrm{Mg}$ unit does not dissociate and segregates as a defect cluster. If however, as our results seem to indicate, $\mathrm{Mg}$ dopants and $\mathrm{O}$ vacancies can move more or less independently, both the $\mathrm{Mg}$ and the $\mathrm{O}$ vacancy concentration should be considered in the derivation (see also Supplementary Information section S6). Eq. (4) thus becomes Eq. (10) for totally dissociated $\mathrm{Mg}-\mathrm{O}_{\mathrm{vac}}-\mathrm{Mg}$ (See Supplementary Information section S5).

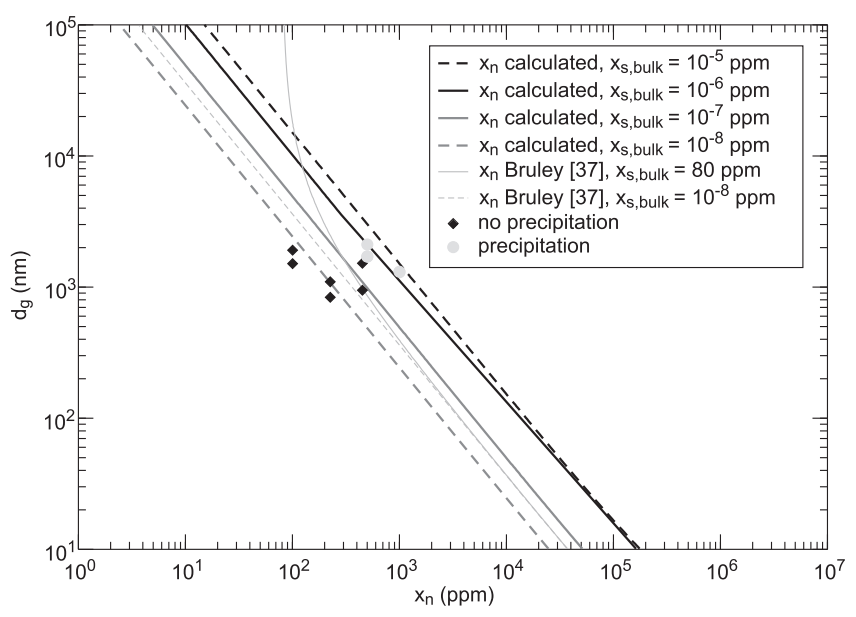

Fig. 9. Calculated nominal La solubility limit for different grain sizes calculated with different supposed bulk solubilities along with experimental values taken from Ref. 1,37,42,43,45-47.

as shown in Fig. 9. Comparison of the calculated curves with experimental precipitation/no precipitation data points indicates a bulk solubility of La between $10^{-6}$ and $10^{-7} \mathrm{ppm}$, which essentially means that $\mathrm{La}$ is not soluble in perfect bulk $\alpha-\mathrm{Al}_{2} \mathrm{O}_{3}$. In real crystals La solubility is likely to be higher due to the presence of impurities and intrinsic crystalline defects, such as vacancies and dislocations. Given the size of La (1.03 $\AA$ ), which is nearly double that of $\mathrm{Al}(0.54 \AA)$, the limited solubility in perfect $\alpha-\mathrm{Al}_{2} \mathrm{O}_{3}$ single crystals seems reasonable. However more experimental data would be necessary to assess the accuracy of the predicted La bulk solubility.

$x_{\mathrm{Mg}, \text { bulk }}=\sqrt{3}\left[x_{\mathrm{Mg}, i} \sqrt{\frac{x_{\mathrm{Mg}, i}}{3+2 x_{\mathrm{Mg}, i}}} \cdot \exp \left(\frac{1}{k T}\left(\Delta H_{\text {seg }, i}+x_{i}\left(x_{i}+1\right) \frac{\partial \Delta H_{\text {seg }, i}}{\partial x_{i}}\right)\right)\right]^{\frac{2}{3}}$

In Fig. 8 results for dissociated defect clusters obtained with Eq. (10) for bulk solubilities of both $300 \mathrm{ppm}$ (solid grey curve) and $132 \mathrm{ppm}$ (dashed black curve) are shown. While this inclusion of configurational entropy for the oxygen vacancies results in slightly lower solubilities, the effect is small and cannot fully account for the difference between simulation and experiment.

\subsubsection{Lanthanum}

As already mentioned, for La the bulk solubility is not known and available experimental data is scarce. Therefore the nominal solubility has been calculated for a range of bulk solubilities

\subsubsection{Consequences for microstructure development}

Table 5 summarizes grain boundary concentrations, enthalpies of segregation and grain boundary energies calculated using Eq. (9) for the three more general high-energy boundaries. It is very interesting to note that for some of the $\mathrm{Mg}$ and La doped grain boundaries the grain boundary energy turns negative. Although Eq. (9) is only approximate and according to Fig. 8 the $\mathrm{Mg}$ grain boundary concentration is likely to be overestimated, the magnitude of these changes 
indicates that these particular grain boundary structures or complexions are highly favorable and that their proportion in the microstructure should increase. A maximization of grain boundary area will occur by adoption of a finer microstructure, thus maximizing the specific grain boundary area. Below the solubility limit, this effect will complement the well-known solute drag effect in reducing (and possibly even inverting) grain growth. The increase in grain boundary energy anisotropy however is also likely to result in the growth of anisotropic grains.

\section{Conclusions}

In the first part of this work segregation of some of the industrially most relevant dopants towards surfaces and grain boundaries in alumina was investigated by means of energy minimization calculations. Where available the results are in good agreement with experimental findings. The investigated lanthanide elements ( $\mathrm{La}, \mathrm{Gd}, \mathrm{Yb}$ ) show a strong tendency for segregation and their mechanism on microstructure development in alumina may be understood in terms of blocking of diffusion sites as well as dislocation motion in the grain boundary region. $\mathrm{La}, \mathrm{Gd}$ and $\mathrm{Yb}$ show a tendency for formation of complete layers at low-energy, low $\Sigma$ grain boundaries, as opposed to previously reported patterns for the slightly smaller Y. ${ }^{6,21}$ For more general grain boundaries these high concentrations are not observed although local minima may exist.

Magnesium being much smaller shows a lower tendency for segregation and charge compensating oxygen vacancies are only loosely bound to $\mathrm{Mg}$ ions. This explains the experimentally observed role of $\mathrm{Mg}$ to enhance diffusion, as dopant segregation will result in a high concentration of mobile diffusion vehicles in the grain boundary region. The suppression of abnormal grain growth due to $\mathrm{Mg}$ segregation can be rationalized by the stronger tendency for segregation to high-energy grain boundaries, thus lowering their grain boundary energy and leading consequently to less anisotropic interfacial energies and more equiaxed grains.

None of the segregated dopants adopt structures matching any of the possible precipitate phases. This indicates that segregation layers will not directly act as nucleation sites for second phase precipitates but are rather the thermodynamically stable structure (complexion) for the respective type of grain boundary and dopant concentration.

Based on the energy minimization results a Monte-Carlo based approach has been developed to assess the nominal solubility of $\mathrm{Y}, \mathrm{La}$ and $\mathrm{Mg}$ dopants as a function of the grain size and bulk concentration. When considering only high- $\Sigma$ boundaries, which should be more representative for general grain boundaries in an alumina microstructure, a reasonable agreement with experiment is obtained for $\mathrm{Y}, \mathrm{La}$ and $\mathrm{Mg}$. The model hence allows a prediction of nominal solubilities for doped ceramics and will be useful in optimizing dopant concentrations. The Monte-Carlo model also represents an important step in link- ing atomistic simulation results on isolated grain boundaries to experimental results obtained for real microstructures.

\section{Acknowledgement}

This research was funded by the European Sixth Framework Integrated Project Nanoker No. NMP3-CT-2005-515784.

\section{Appendix A. Supplementary data}

Supplementary data associated with this article can be found, in the online version, at doi:10.1016/j.jeurceramsoc.2011.07.010.

\section{References}

1. Thompson AM, Soni KK, Chan HM, Harmer MP, Williams DB, Chabala JM, et al. Dopant distributions in rare-earth-doped alumina. J Am Ceram Soc 1997;80:373-6.

2. Yang QH, Zeng ZJ, Xu J, Zhang HW, Ding J. Effect of $\mathrm{La}_{2} \mathrm{O}_{3}$ on microstructure and transmittance of transparent alumina ceramics. J Rare Earths 2006;24:72-5.

3. Harmer MP. Interfacial kinetic engineering: how far have we come since Kingery's inaugural Sosman address? J Am Ceram Soc 2010;93: 301-17.

4. Kingery WD. Structure and properties of $\mathrm{MgO}$ and $\mathrm{Al}_{2} \mathrm{O}_{3}$ ceramics. Advances in ceramics, vol. 10. Columbus, OH: American Ceramic Society; 1984.

5. West GD, Perkins JM, Lewis MH. Characterisation of fine-grained oxide ceramics. J Mater Sci 2004;39:6687-704.

6. Galmarini S, Aschauer U, Bowen P, Parker SC. Atomistic simulation of Y-doped $\alpha$-alumina interfaces. J Am Ceram Soc 2008;91: 3643-51.

7. Aschauer U, Bowen P. Theoretical assessment of Nd:YAG ceramic laser performance by microstructural and optical modeling. J Am Ceram Soc 2010;93:814-20.

8. Aschauer U, Bowen P, Parker SC. Atomistic modeling study of surface segregation in Nd:YAG. $J$ Am Ceram Soc 2006;89: 3812-6.

9. Aschauer U, Bowen P, Parker SC. Surface and mirror twin grain boundary segregation in Nd:YAG: an atomistic simulation study. J Am Ceram Soc 2008;91:2698-705.

10. Born M, Huang K. Dynamical theory of crystal lattices. Oxford, UK: Oxford University Press; 1954.

11. Watson GW, Kelsey ET, deLeeuw NH, Harris DJ, Parker SC. Atomistic simulation of dislocations, surfaces and interfaces in MgO. J Chem Soc Faraday Trans 1996;92:433-8.

12. Dick BG, Overhauser AW. Theory of the dielectric constants of alkali halide crystals. Phys Rev 1958;112:90-103.

13. Lewis GV, Catlow CRA. Potential models for ionic oxides. J Phys $C$ 1985;18:1149-61.

14. Liu RS, Shi WC, Cheng YC, Huang CY. Crystal structures and peculiar magnetic properties of $\alpha$ - and $\gamma-\mathrm{Al}_{2} \mathrm{O}_{3}$ powders. Mod Phys Lett $B$ 1997;11:1169-74.

15. Mackrodt WC, Tasker PW. Segregation isotherms at the surfaces of oxides. J Am Ceram Soc 1989;72:1576-83.

16. Mott MF, Littleton MJ. Conduction in polar crystals. I. Electrolytic conduction in solid salts. Trans Faraday Soc 1938;34: 485-99.

17. Gale JD. GULP: a computer program for the symmetry-adapted simulation of solids. J Chem Soc Faraday Trans 1997;93:629-37.

18. Gale JD, Rohl AL. The general utility lattice program (GULP). Mol Simul 2003;29:291-341 
19. Gemming T, Nufer S, Kurtz W, Rühle M. Structure and chemistry of symmetrical tilt grain boundaries in $\alpha-\mathrm{Al}_{2} \mathrm{O}_{3}$ : I, bicrystals with "clean" interface. J Am Ceram Soc 2003;86:581-9.

20. Gemming T, Nufer S, Kurtz W, Rühle M. Structure and chemistry of symmetrical tilt grain boundaries in $\alpha-\mathrm{Al}_{2} \mathrm{O}_{3}$ : II, bicrystals with $\mathrm{Y}$ at the interface. J Am Ceram Soc 2003;86:590-4.

21. Buban JP, Matsunaga K, Chen J, Shibata N, Ching WY, Yamamoto T, et al. Grain boundary strengthening in alumina by rare earth impurities. Science 2006;311:212-5.

22. Polak M, Rubinovich L. The interplay of surface segregation and atomic order in alloys. Surf Sci Rep 2000;38:127-94.

23. Galassi M, Davies J, Theiler J, Gough B, Jungman G, Alken P, et al. GNU scientific library reference manual. Third Edition Network Theory Ltd.; 2009.

24. Shchur LN, Butera P. The RANLUX generator: resonances in a random walk test. Int J Mod Phys C 1998;9:607-24.

25. Matsumoto M, Wada I, Kuramoto A, Ashihara H. Common defects in initialization of pseudorandom number generators. ACM Trans Model Comput Simul 2007;17:ARTN 15.

26. Wand MP, Jones MC. Kernel smoothing. London: Chapman \& Hall; 1995.

27. Marmier A, Parker SC. Ab initio morphology and surface thermodynamics of $\alpha-\mathrm{Al}_{2} \mathrm{O}_{3}$. Phys Rev B 2004;69:115409.

28. Kitayama M, Glaeser AM. The Wulff shape of alumina: III, undoped alumina. J Am Ceram Soc 2002;85:611-22.

29. Choi JH, Kim DY, Hockey BJ, Wiederhorn SM, Handwerker CA, Blendell JE, et al. Equilibrium shape of internal cavities in sapphire. J Am Ceram Soc 1997;80:62-8.

30. Eng PJ, Trainor TP, Brown GE, Waychunas GA, Newville M, Sutton $\mathrm{SR}$, et al. Structure of the hydrated $\alpha-\mathrm{Al}_{2} \mathrm{O}_{3}\left(\begin{array}{llll}0 & 0 & 0 & 1\end{array}\right)$ surface. Science 2000;288:1029-33.

31. Trainor TP, Eng PJ, Brown GE, Robinson IK, De Santis M. Crystal truncation rod diffraction study of the $\alpha-\mathrm{Al}_{2} \mathrm{O}_{3}$ (1(1)over-bar-0 2) surface. Surf Sci 2002;496:238-50.

32. Cho JY, Rickman JM, Chan HM, Harmer MP. Modeling of grain-boundary segregation behavior in aluminum oxide. J Am Ceram Soc 2000;83: 344-52.

33. Bouchet D, Lartigue-Korinek S, Molins R, Thibault J. Yttrium segregation and intergranular defects in alumina. Philos Mag 2006;86: 1401-13.

34. Shannon RD. Revised effective ionic-radii and systematic studies of interatomic distances in halides and chalcogenides. Acta Crystallogr Sect A 1976;32:751-67.

35. Fabris $\mathrm{S}$, Elsässer C. First-principles analysis of cation segregation at grain boundaries in $\alpha-\mathrm{Al}_{2} \mathrm{O}_{3}$. Acta Mater 2003;51:71-86.

36. Elsässer C, Marinopoulos AG. Substitutional cation impurities in $\alpha-\mathrm{Al}_{2} \mathrm{O}_{3}$ : ab-initio case study of segregation to the rhombohedral twin boundary. Acta Mater 2001;49:2951-9.

37. Bruley J, Cho J, Chan HM, Harmer MP, Rickman JM. Scanning transmission electron microscopy analysis of grain boundaries in creep-resistant yttrium- and lanthanum-doped alumina microstructures. J Am Ceram Soc 1999;82:2865-70.

38. Cho J, Chan HM, Harmer MP, Rickman JM. Influence of yttrium doping on grain misorientation in aluminum oxide. J Am Ceram Soc 1998;81: 3001-4.

39. Grimmer $\mathrm{H}$, Bonnet $\mathrm{R}$, Lartigue $\mathrm{S}$, Priester $\mathrm{L}$. Theoretical and experimental descriptions of grain-boundaries in rhombohedral $\alpha-\mathrm{Al}_{2} \mathrm{O}_{3}$. Philos Mag A 1990;61:493-509.

40. Swiatnicki W, Lartigue-Korinek S, Laval JY. Grain boundary structure and intergranular segregation in $\mathrm{Al}_{2} \mathrm{O}_{3}$. Acta Metal Mater 1995;43: 795-805.

41. Gülgün MA, Putlayev V, Rühle M. Effects of yttrium doping $\alpha$-alumina: I, microstructure and microchemistry. J Am Ceram Soc 1999;82:1849-56.

42. Fang JX, Thompson AM, Harmer MP, Chan HM. Effect of yttrium and lanthanum on the final-stage sintering behavior of ultrahigh-purity alumina. J Am Ceram Soc 1997;80:2005-12.

43. Stuer M, Zhao Z, Aschauer U, Bowen P. Transparent polycrystalline alumina using spark plasma sintering: effect of $\mathrm{Mg}, \mathrm{Y}$ and La doping. J Eur Ceram Soc 2010;30:1335-43.
44. Cho JH, Harmer MP, Chan HM, Rickman JM, Thompson AM. Effect of yttrium and lanthanum on the tensile creep behavior of aluminum oxide. $J$ Am Ceram Soc 1997;80:1013-7.

45. Cho J, Wang CM, Chan HM, Rickman JM, Harmer MP. Role of segregating dopants on the improved creep resistance of aluminum oxide. Acta Mater 1999;47:4197-207.

46. Cho J, Wang CM, Chan HM, Rickman JM, Harmer MP. Improved tensile creep properties of yttrium- and lanthanum-doped alumina: a solid solution effect. J Mater Res 2001;16:425-9.

47. Yoshida H, Ikuhara Y, Sakuma T. High-temperature creep resistance in rare-earth-doped, fine-grained $\mathrm{Al}_{2} \mathrm{O}_{3}$. J Mater Res 1998;13:2597-601.

48. Yoshida H, Matsunaga K, Yamamoto T, Ikuhara Y, Sakuma T. Dopant effect on the high-temperature grain boundary sliding in alumina. Superplast $A d v$ Mater 2003;447-448:299-304.

49. Lartigue-Korinek S, Carry C, Priester L. Multiscale aspects of the influence of yttrium on microstructure, sintering and creep of alumina. J Eur Ceram Soc 2002;22:1525-41.

50. Yoshida H, Matsunaga K, Yamamoto T, Ikuhara Y, Sakuma T. Dopant effect on the high-temperature grain boundary sliding in alumina. Superplast $A d v$ Mater 2003;447-484:299-304.

51. Miller L, Avishai A, Kaplan WD. Solubility limit of $\mathrm{MgO}$ in $\mathrm{Al}_{2} \mathrm{O}_{3}$ at 1600 degrees C. J Am Ceram Soc 2006;89:350-3.

52. Kaneko K, Kato T, Kitayama M, Tomokiyo Y. Precipitation of $\mathrm{MgO} \cdot n \mathrm{Al}_{2} \mathrm{O}_{3}$ in $\mathrm{Mg}$-doped $\alpha-\mathrm{Al}_{2} \mathrm{O}_{3}$ under electron irradiation. $J \mathrm{Am}$ Ceram Soc 2003;86:161-8.

53. Gavrilov KL, Bennison SJ, Mikeska KR, Levi-Setti R. Grain boundary chemistry of alumina by high-resolution imaging SIMS. Acta Mater 1999;47:4031-9.

54. Sung CM, Wei GC, Ostreicher KJ, Rhodes WH. Segregation of magnesium to the internal surface of residual pores in translucent polycrystalline alumina. J Am Ceram Soc 1992;75:1796-800.

55. Monceau D, Petot C, Petotervas G, Fraser JW, Graham MJ, Sproule GI. Surface segregation and morphology of $\mathrm{Mg}$-doped $\alpha$-alumina powders. $J$ Eur Ceram Soc 1995; 15:851-8.

56. Mukhopadhyay SM, Jardine AP, Blakely JM, Baik S. Segregation of magnesium and calcium to the (1010) prismatic surface of magnesiumimplanted sapphire. J Am Ceram Soc 1988;71:358-62.

57. Baik S. Segregation of $\mathrm{Mg}$ to the $(0001)$ surface of single-crystal alumina—quantification of AES results. JAm Ceram Soc 1986;69:C101-3.

58. Roy SK, Coble RL. Solubilities of magnesia, titania and magnesium titanate in aluminum oxide. J Am Ceram Soc 1968;51:1-6.

59. Berry KA, Harmer MP. Effect of MgO solute on microstructure development in $\mathrm{Al}_{2} \mathrm{O}_{3}$. J Am Ceram Soc 1986;69:143-9.

60. Bennison SJ, Harmer MP. Effect of magnesia solute on surface-diffusion in sapphire and the role of magnesia in the sintering of alumina. J Am Ceram Soc 1990;73:833-7.

61. Hewson CW, Kingery WD. Effect of $\mathrm{MgO}$ and $\mathrm{MgTiO}_{3}$ doping on diffusion-controlled creep of polycrystalline aluminum oxide. J Am Ceram Soc 1967;50:218-9.

62. Rodel J, Glaeser AM. Anisotropy of grain-growth in alumina. J Am Ceram Soc 1990;73:3292-301.

63. McCune RC, Donlon WT, Ku RC. Yttrium segregation and YAG precipitation at surfaces of yttrium-doped $\alpha-\mathrm{Al}_{2} \mathrm{O}_{3}$. J Am Ceram Soc 1986;69:C196-9.

64. Cawley JD, Halloran JW. Dopant distribution in nominally yttrium-doped sapphire. J Am Ceram Soc 1986;69:C195-6.

65. Carry C, Bowen P, Herbst F, Legros C. The effect of yttrium and zirconium on sintering of a transition alumina. In: Sintering science and technologies. 2000. p. 177-82.

66. Gruffel P, Carry C. Effect of grain size on yttrium grain boundary segregation in fine-grained alumina. J Eur Ceram Soc 1993;11:189-99.

67. Sato E, Carry C. Yttria doping and sintering of submicrometer-grained $\alpha$-alumina. J Am Ceram Soc 1996;79:2156-60.

68. Yoshida H, Ikuhara Y, Sakuma T. High-temperature creep resistance in lanthanoid ion-doped polycrystalline $\mathrm{Al}_{2} \mathrm{O}_{3}$. Philos Mag Lett 1999;79:249-56.

69. Bae SI, Baik S. Critical concentration of $\mathrm{MgO}$ for the prevention of abnormal grain-growth in alumina. J Am Ceram Soc 1994;77:2499-504. 
70. Legros C, Herbst F, Carry C. Influence of magnesia on sintering of transition alumina. In: EUROMAT. 2000. p. 23-8.

71. Peelen GJ. Influence of $\mathrm{MgO}$ on the evolution of the microstructure of $\mathrm{Al}_{2} \mathrm{O}_{3}$. Mater Sci Res 1975;10:443-53.

72. Johnson WC. Mg distributions at grain-boundaries in sintered alumina containing $\mathrm{MgAl}_{2} \mathrm{O}_{4}$ precipitates. J Am Ceram Soc 1978;61:234-7.

73. Handwerker CA, Dynys JM, Cannon RM, Coble RL. Dihedral angles in magnesia and alumina - distributions from surface thermal grooves. $J \mathrm{Am}$ Ceram Soc 1990;73:1371-7.
74. Lin FJT, DeJonghe LC, Rahaman MN. Initial coarsening and microstructural evolution of fast-fired and $\mathrm{MgO}$-doped $\mathrm{Al}_{2} \mathrm{O}_{3}$. J Am Ceram Soc 1997;80:2891-6.

75. Wang CM, Cargill GS, Chan HM, Harmer MP. Structural features of Y-saturated and supersaturated grain boundaries in alumina. Acta Mater 2000; 48:2579-91.

76. Gülgün MA, Voytovych R, MacLaren I, Rühle M, Cannon RM. Cation segregation in an oxide ceramic with low solubility: yttrium doped $\alpha$-alumina. Interface Sci 2002;10:99-110. 